\title{
WestVirginiaUniversity
}

THE RESEARCH REPOSITORY @ WVU

Graduate Theses, Dissertations, and Problem Reports

2004

\section{Caregiver factors related to unintentional burn injuries in young children}

Karen E. Joseph

West Virginia University

Follow this and additional works at: https://researchrepository.wvu.edu/etd

\section{Recommended Citation}

Joseph, Karen E., "Caregiver factors related to unintentional burn injuries in young children" (2004).

Graduate Theses, Dissertations, and Problem Reports. 2140.

https://researchrepository.wvu.edu/etd/2140

This Dissertation is protected by copyright and/or related rights. It has been brought to you by the The Research Repository @ WVU with permission from the rights-holder(s). You are free to use this Dissertation in any way that is permitted by the copyright and related rights legislation that applies to your use. For other uses you must obtain permission from the rights-holder(s) directly, unless additional rights are indicated by a Creative Commons license in the record and/ or on the work itself. This Dissertation has been accepted for inclusion in WVU Graduate Theses, Dissertations, and Problem Reports collection by an authorized administrator of The Research Repository @ WVU.

For more information, please contact researchrepository@mail.wvu.edu. 
Caregiver Factors Related to Unintentional Burn Injuries in Young Children

\author{
Karen E. Joseph \\ Dissertation submitted to the \\ College of Arts and Sciences \\ at West Virginia University \\ in partial fulfillment of the requirements \\ for the degree of
}

Doctor of Philosophy
in
Child Clinical Psychology

JoNell Strough, Ph.D., Chair

Christina D. Adams, Ph.D.

Tracy L. Morris, Ph.D.

Stanley H. Cohen, Ph.D.

Harvey Slater, M.D.

Department of Psychology

Morgantown, West Virginia

2004

Keywords: Pediatric Burn Injuries, Young Children, Injury Prevention, Parent Factors, Home Safety Knowledge, Safety Behavior

Copyright 2004 Karen E. Joseph 


\begin{abstract}
Caregiver Factors Related to Unintentional Burn Injuries in Young Children
\end{abstract}

Karen E. Joseph

The main purpose of this study was to examine the contribution of caregiver behavioral versus demographic factors to the prediction of a child burn injury and caregiver safety behavior using a sample of primary caregivers of children (aged 0-5 years) with a burn injury (case participants) or without one (comparison participants). Case participants $(n=30)$ were recruited from a burn center in the Northeastern United States, whereas comparison participants $(n=30)$ were recruited from pediatric facilities, balanced to cases by child age, gender, race, and geography, and caregiver socioeconomic and marital status. Measures of demographic and burn information, caregiver psychopathology, parenting stress, and caregiver home safety knowledge and behavior were completed as close to the time of enrollment as possible, with safety knowledge and behavior obtained by home interviews and observation. Burns (50\% scalds) were mostly second and third degree, with their total body surface area ranging from 1-29\%. Findings revealed significantly greater safety knowledge among comparison versus case participants, with caregiver safety knowledge the only factor significantly related to child burn outcome. In hierarchical regression analyses predicting caregiver safety behaviors, safety knowledge was a significant predictor of supervision, above and beyond other predictors, and parenting stress and certain demographic variables together accounted for a significant proportion of the variance in home safety. These findings suggest that parental behavioral factors may improve the prediction of early childhood burns and caregiver safety behavior over that afforded by demographic variables alone. Limitations and implications for prevention are discussed. 


\section{Dedication}

This dissertation is dedicated in loving memory and gratitude to my parents, Barbara and Robert Joseph, for their love, support, encouragement, and belief in me, as well as their extraordinary courage, strength, and grace during their lifetime. My greatest role models and heroes, always. 


\section{Acknowledgements}

I would like to express my sincere thanks and gratitude to Christina D. Adams, Ph.D., for her unwavering support and encouragement, genuine interest in my learning, sound guidance, and confidence in me throughout this project. From original chair to functional chair following her move to another state, she has been a most loyal, dedicated, and positive supervisor who I greatly respect and appreciate. I cannot thank her enough. I also would like to thank JoNell Strough, Ph.D., Tracy Morris, Ph.D., Stanley Cohen, Ph.D., and Harvey Slater, M.D., for their thoughtful and helpful contributions to my study as members of my dissertation committee. Their input and support have been invaluable. An additional thanks to Dr. Strough and Dr. Cohen for stepping into new roles (Dr. Strough as chair and Dr. Cohen as a committee member) when original committee members moved away.

I thank Dr. Slater, Patricia Manni, R.N., B.S.N., and Helenanne Hochendoner, R.N., for their professional reviews of newly-developed or modified questionnaires for this study. Their specific feedback was most helpful toward improving the content validity of these measures.

I extend many thanks to Dr. Slater, Patricia Manni, R.N., B.S.N., and other burn care staff at the study burn unit; Lawrence Butler, M.D., and staff at his pediatric clinic; and Nalini Robinson, M.D., and her staff for welcoming me where they work and allowing me to recruit their patients. Dr. Slater, Patricia Manni, R.N., B.S.N., and Dr. Robinson are recognized especially for their active involvement in recruitment.

I was very fortunate to have the aid of exceptional research assistants. I would like to thank Melissa DeMore, M.A., and Jill MacLaren, M.A., for their generous assistance with participant recruitment, medical chart review, and home data collection. Many thanks to Carrie Muller, B.A., for her conscientious work as a reliability observer and coder. Thanks also to Dara 
Skidmore, B.S., for her assistance with observer reliability. I always will be deeply appreciative of the time and dedication of these individuals.

I greatly appreciate financial assistance for my dissertation from the Alumni Fund at West Virginia University (WVU), Department of Psychology, and the Office of Academic Affairs through the Eberly College of Arts and Sciences at WVU. I also am very grateful for generous financial support from the Western Pennsylvania Hospital Foundation, facilitated by Dr. Slater. This latter funding covered the cost of participant payment.

Thank you to the pilot families and study participants who generously gave their time to this research. This study would not be possible if not for them.

Finally, I would like to convey heartfelt thanks to my family, friends, and fiancé, Matt, for standing by me with love and encouragement through this project. They have been my foundation, my anchor, my haven. A very special thanks to Matt, in particular, for his loyalty, patient understanding, love, and humor; for all the early Saturday morning rides to the airport and send-offs before I flew to Pittsburgh for data collection, laundry he did, meals he cooked, and phone calls he took to help me see this project through. 
Table of Contents

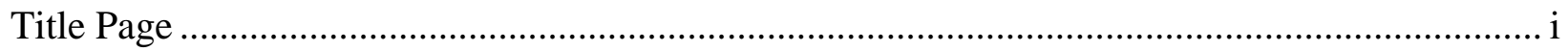

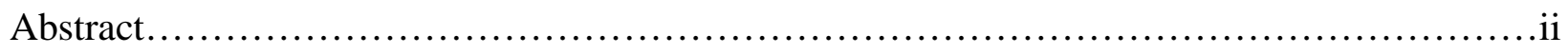

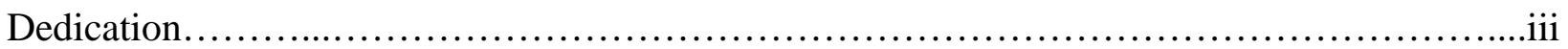

Acknowledgements..................................................................

Table of Contents...................................................................

List of Tables.................................................................. viii

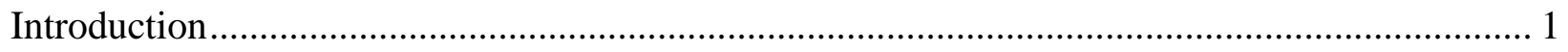

Characteristics of Unintentional Early Childhood Burns ........................................... 3

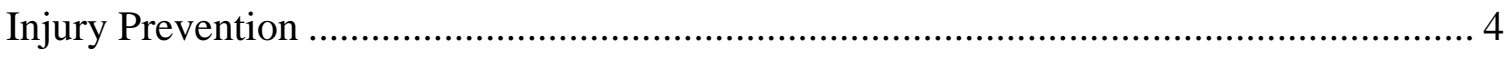

Parental Correlates of Child Injuries Collectively and Burns Specifically...................... 6

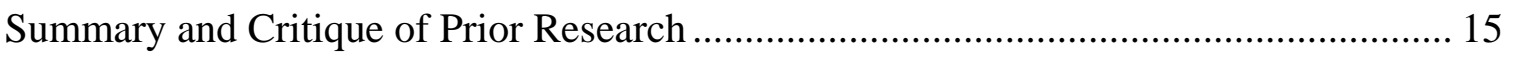

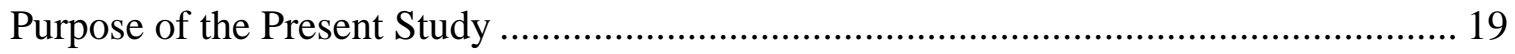

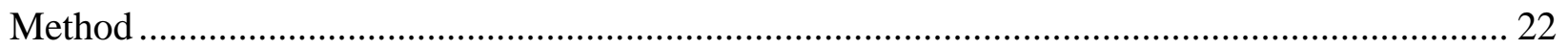

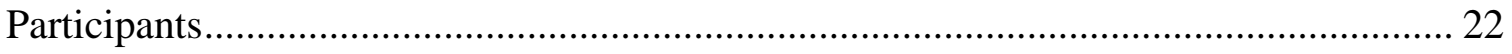

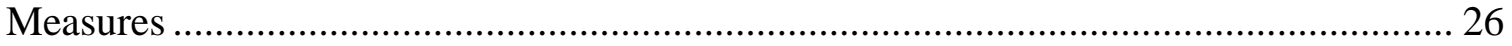

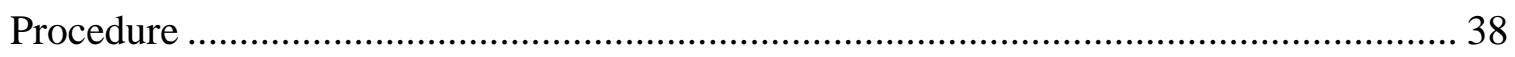

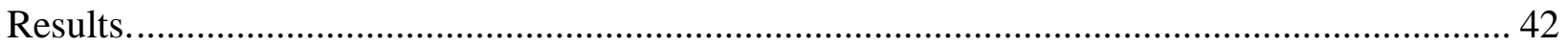

Sample Characteristics....................................................42

Relation between Predictors and the Outcome of a Pediatric Burn....................46

Relation between Predictors and Home Safety Behaviors..........................47

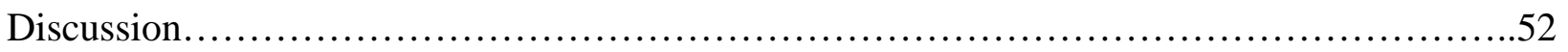

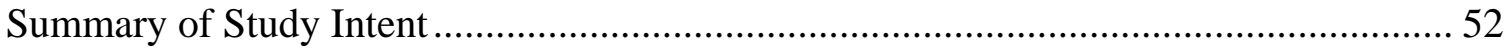


Summary of Main Findings................................................... 52

Group Differences in Caregiver Psychological and Behavioral Functioning................... 53

Relation between Predictors and the Outcome of a Pediatric Burn.....................61

Relation between Predictors and Supervision....................................63

Relation between Predictors and Home Hazard Control..............................65

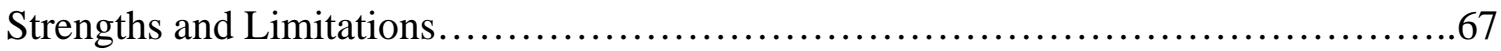

Additional Directions for Future Research.......................................69

Implications for Prevention.................................................... 70

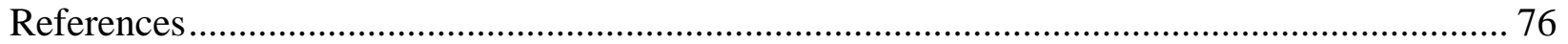

Appendices....................................................................... 85

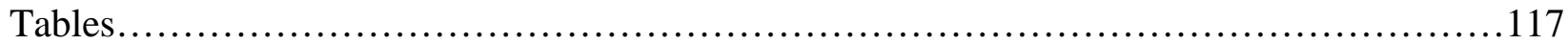




\section{List of Tables}

Table 1. Balanced Demographic Variables by Group.................................117

Table 2. Family Demographic and Household Information.............................118

Table 3. Caregiver Psychopathology, Parenting Stress, and Home Safety Knowledge and Behaviors.................................................................119

Table 4. Clinically Significant Scales Endorsed by Participants on the Personality Assessment

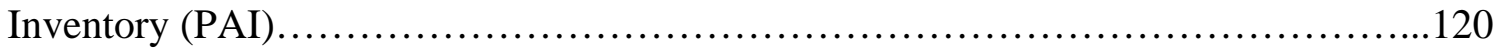

Table 5. Correlations between Predictor Variables and Outcome Variables...................121

Table 6. Pictorial Representation of Proposed Discriminant Function and Hierarchical Regression Analyses............................................................... 122

Table 7. Summary of Hierarchical Regression Analysis for Variables Predicting Caregiver Supervision...........................................................123

Table 8. Summary of Hierarchical Regression Analysis for Variables Predicting Caregiver Home Hazard Control.................................................................... 124 


\section{Caregiver Factors Related to Unintentional Burn Injuries in Young Children}

Pediatric burn injuries are the third leading cause of unintentional death in children in the United States (U.S.), exceeded only by the number of children killed in motor vehicle crashes and drownings (Libber \& Stayton, 1984). Annually, an estimated 2,500 children in the U.S. die consequent to burn injuries (Sharp, 1993). Worldwide, infants and toddlers, in particular, sustain a disproportional number of burn injuries as evidenced by research from developed countries (e.g., the U.S.; Libber \& Stayton) and less developed ones (e.g., Nigeria; Laditan, 1987). These young children have twice as much risk of dying from burns than school-age children, and three times as much risk of a fatality from burns than adolescents (Guyer \& Ellers, 1990). Burns also contribute to nonfatal childhood injury (Sullivan, Cole, Lie, \& Twomey, 1990). In the U.S., an estimated 40,000 children are hospitalized for burns each year with 21,000 of these children requiring intensive treatment (Luther \& Price, 1981). Annually, 10,000 children in the U.S. endure permanent disability from a burn (Sharp).

There are many acute physical and psychological problems that may result from a pediatric burn. Intensive medical interventions often are necessary in acute burn care (Tarnowski, 1994). Daily dressing changes and burn debridement cause excruciating pain to patients (McLoughlin \& McGuire, 1990) and often are accompanied by anticipatory anxiety and overt distress (Tarnowski \& Rasnake, 1990). Not surprisingly, the acute phase of burn care often is exceptionally stressful for caregivers of the pediatric patient (Luther \& Price, 1981).

It is not uncommon for pediatric burn survivors to experience prolonged rehabilitation with medical and psychological challenges (Tarnowksi, 1994). Even a small burn (e.g., to the palm of one's hand) can have negative longterm sequelae and is considered a major injury by the American Burn Association (Barret, Desai, \& Herndon, 2000). Burn care after hospitalization 
often consists of medical regimens (e.g., the use of pressure garments), which may be prescribed long-term, as well as multiple follow-up medical visits. Contractures and hypertrophic scars often develop during healing (Rossi, Braga, Barruffini, \& Carvalho, 1998). These outcomes frequently lead to loss of function and disfigurement and are associated with psychological problems (Rossi et al.). Children with severe burns may undergo reconstructive operations for years after the burn incident, creating a continuous barrage of physical and psychological hurdles (Tarnowski). Not surprisingly, psychosocial difficulties have been noted in pediatric burn survivors (Blakeney, 1994). Even children with less severe burns may experience psychological disturbances (Tarnowski \& Rasnake, 1994). Burn injuries of varying degrees of severity also have been associated with problematic psychological functioning in family members (Crawley, 1996; Tarnowski \& Rasnake).

Furthermore, the financial costs of pediatric burns are stunning. Extended and sometimes repeated hospitalizations and permanent disabilities due to pediatric burns translate into an exorbitant number of school absences and productive workdays lost, thereby increasing societal burden (Cronin, Butler, McHugh, \& Edwards, 1996). In 1985, pediatric burn mortality and morbidity resulted in an estimated loss of 101,000 life years and $\$ 3.5$ billion to society (McLoughlin \& McGuire, 1990).

The focus of the present study is to understand better parental factors associated with unintentional burns in young children, the latter referring to children ages 5 years and younger. While both intentional and unintentional burn injuries represent serious public health concerns (Fratianne \& Brandt, 1994), each type warrants a distinct analysis in terms of related parental factors. Similarly, while burns among youth of all ages warrant attention, burns among young children require a separate analysis because they generally are different in nature (e.g., type, 
location) than burns in older youth (Green, Fairclough, \& Sykes, 1984) and in turn, may have unique parental correlates. Below, a review of characteristics of unintentional burns in young children, child injury prevention strategies and models, and parental correlates of pediatric injuries both in general and specific to burns is provided as a rationale for the present investigation. Both demographic parental correlates (e.g., income), which have been the predominant focus of previous study, followed by psychological/behavioral parental correlates, which have been under-studied relatively, especially in the burn injury literature, are discussed.

\section{Characteristics of Unintentional Early Childhood Burns}

Children between the ages of 0 and 5 years sustain scald burns more frequently than any other type of burn (Chedekel, Rizzone, \& Antoon, 1998). As an example, Simon and Baron (1994) found that $64 \%$ of children aged 0-5 years who were treated for burn injuries at a U.S. burn facility over a 1-year period were scalded. Common scald agents in early childhood are liquids, foods, and bath water (Crawley, 1996; Fukunishi et al, 2000; Turegun, Celikoz, Nisanci, \& Selmanpakoglu, 1997). Infants most frequently receive a scald burn while bathing, whereas toddlers most frequently are scalded by hot liquid, food, or tap water (Sharp, 1993). The kitchen (Rossi et al., 1998) and bathroom (Crawley) have been found to be the most common locations where scalds to young children occur.

Types of burns other than scalds incurred by young children include contact with hot objects (e.g., curling iron), flame, chemical, electrical, and flash from a fire (Chedekel et al., 1998; Simon \& Baron, 1994). Like scalds, other burns sustained by young children occur indoors more commonly than outdoors (Tarnowski, 1994). Among children aged 0-2 years, 95\% of burn injuries occur indoors (Tarnowski). Research has not elucidated locations in the home where burns other than scalds are most likely to occur. 


\section{Injury Prevention}

\section{Strategies}

Injuries, like many diseases, are not chance events; rather, they can be predicted and controlled (Guyer \& Gallagher, 1985). In 1985, 75\% of burn fatalities in children under age 4 years could have been prevented (Sharp, 1993). Both passive (e.g., water heater temperature preset by apartment managers) and active (e.g., parent adjusting bath water temperature) approaches to injury prevention have been recognized (Christophersen \& Purvis, 1991). Damashek and Peterson (2002) recommend placing injury prevention strategies on a continuum from completely passive to completely active rather than conceptualizing them as a dichotomy (i.e., passive or active) to better illustrate the range of effort involved in various strategies. For example, constant supervision requires more active effort than putting up a kitchen safety gate; yet, both are types of active strategies. Because active strategies require directed involvement and some degree of effort, they generally are less effective than passive ones (Hazinski, Francescutti, Lapidus, Micik, \& Rivara, 1993). There are instances, however, when passive strategies are not possible (Christophersen \& Purvis). For example, in most homes, it is not possible to remove all burn injury sources (e.g., stove), and there will be some risks (e.g., being burned by hot food) that passive approaches cannot lessen (Tremblay \& Peterson, 1999). Optimal injury control demands both passive and active strategies (Christophersen \& Purvis).

\section{A Classic Model}

A widely cited epidemiological model that highlights factors contributing to injury is that of Haddon (1980). Three categories of consideration in Haddon's model are (a) the injury recipient or host, (b) the agent of the injury, and (c) the environment (Christophersen \& Purvis, 
1991). Each category influences the occurrence of (a) a risk situation (e.g., infant in a baby walker), (b) an injury, and (c) consequences (e.g., disability; Rivara \& Mueller, 1987).

The environment (e.g., toys on the kitchen floor) influences how the host (e.g., toddler) and the agent (e.g., hot tea in a mother's hand) interact (Rivara \& Mueller, 1987). For this reason, the environment has been an important area for study in child injury prevention. Parents or other primary caregivers control the home environment of young children (Matheny, 1987). Although research has found a relation between child behavior and child injury, it is not clear whether child behavior contributes additionally to child injury after accounting for parental and home factors (Matheny). Findings from a recent study actually suggest that young children with difficult behaviors (e.g., hyperactivity) may be protected from injury by positive parenting (e.g., structured activities for child) alone (Schwebel, Brezausek, Ramey, \& Ramey, 2004).

One limitation of the model by Haddon (1980) is that it does not account for parental supervision, which researchers (e.g., Damashek \& Peterson, 2002; Wortel, de Geus, Kok, \& van Woerkum, 1994) increasingly have recognized as a critical factor in child injury prevention. Supervision, in a different way than the environment, influences how, if at all, the host interacts with injury agents. Supervision can prevent a risk situation from becoming an injury (Wortel et al.); in fact, some injuries only can be prevented with supervision (Damashek \& Peterson). At the same time, parental supervision is likely to vary based on other demands (e.g., needs of another child) and constant supervision at all times is unrealistic (Wortel et al.); thus, the importance of parental environmental control of hazards as much as possible cannot be overstated. The present study focuses on the environmental factor in Haddon's model (i.e., the home environment of young children as controlled by parents), as well as other parental factors (e.g., supervision) in relation to unintentional burn injuries in young children. 


\section{Parental Correlates of Child Injuries Collectively and Burns Specifically}

\section{Sociodemographic Variables}

General injury literature. U.S. studies have documented a significant, negative relation between caregiver age and child injuries (Brenner, Overpeck, Trumble, DerSimonian, \& Berendes, 1999; Klauber, Barrett-Connor, Hofstetter, \& Micik, 1986), even after adjusting for child age (Klauber et al.) and other variables such as child birth weight (Brenner et al.). Parental education also has been related negatively to childhood injuries (Laffoy, 1997; Matheny, 1988) and injury fatalities (Bobak, Pikhart, \& Koupilova, 2000; Brenner et al.) after controlling for other covariates (e.g., maternal marital status; Bobak et al.). However, a positive relation between maternal education and child injury also has been found (Harel, 1988; Kohen, Soubhi, \& Raina, 2000). Harel concludes that well-educated mothers might be more likely than less educated ones to report minor events as injuries. With respect to employment, significantly more injuries have been found among U.S. children of mothers who are unemployed versus employed (Dal Santo, Goodman, Glik, \& Jackson, 2004; Harel). U.S. mothers in the home, due to distractions and responsibilities, may be less likely than daycare providers to attend to their children (Harel). Increased risk of child injury also has been found among single mothers (e.g., Kohen et al.). In one Czech study, injury fatalities in infants of unmarried mothers were over two times greater than those in infants of married mothers (Bobak et al.). Whether or not certain, relevant factors were adjusted for in this analysis, however, is unclear.

Additionally, childhood injuries of varying types disproportionately have occurred among certain racial and ethnic minority groups in the U.S. (e.g., Division of Injury Control, Center for Environmental Health and Injury Control, \& Centers for Disease Control, 1990); however minority status often is confounded with other relevant factors (e.g., income) in this research. 
Furthermore, not all studies have found a greater proportion of child injuries among racial and ethnic minority groups. For example, Hispanic children have been found to have significantly fewer injuries as reported by mothers than Caucasian children after adjusting for relevant factors like income (Klauber et al., 1986; Vaughan, Anderson, Agran, \& Winn, 2004), and nonCaucasian children (83\% African American) have been shown to have fewer maternal-reported injuries than Caucasian children after controlling for relevant variables (Dal Santo et al., 2004). Finally, economically disadvantaged children are at greater risk of injury than are economically advantaged ones (Faelker, Pickett, \& Brison, 2000; Kemp \& Sibert, 1997; Laffoy, 1997). As with other demographic variables, however, the research on economic status in relation to child injury often has failed to evaluate potentially confounded variables (e.g., parental education). Additionally, some studies have not identified a significant relation between poverty and child injury (Langley, Silva, \& Williams, 1987; Rivara, 1995). Perhaps it may not be poverty but problems (e.g., lack of safety devices) often associated with poverty that put children at increased risk (Rivara).

Burn injury literature. Unlike the general injury literature, the burn literature suggests that the age of mothers of children with burns may not differ significantly from that of mothers of children without burns (Libber \& Stayton, 1984). Perhaps maternal age is more strongly related to certain non-burn injuries (e.g., poisonings) than it is to burns. Burn injury research has been more consistent than has the general injury literature in showing a significant, negative relation between caregiver education and child burns (El-Badawy \& Mabrouk, 1998; Forjuoh et al., 1995). El-Badawy and Mabrouk’s study is limited by a confound between maternal education and income, and the absence of a control group; however, Forjuoh et al. found that young children with burns in Ghana had mothers with significantly less education than did control 
children pair-matched by age, gender, and geography. The relation between caregiver employment and pediatric burns is less consistent. Libber and Stayton found that mothers of children with burns in the U.S. were not more or less likely to be employed than comparison mothers. Perhaps U.S. mothers in the home are more likely to report a relatively trivial child injury (e.g., a cut) than to report a less common injury like a burn, due to the influence of social desirability. In Greece, however, more employed mothers were found among children with burns than among age- and gender-matched controls (Petridou et al., 1998). Perhaps working mothers in Greece have fewer resources (e.g., daycare) available for child supervision than working mothers in the U.S. Regarding parental marital status, Libber and Stayton found a significantly greater proportion of single mothers among children with burns than would be expected in the general U.S. population. Likewise, in a review of 197 consecutive pediatric burn admissions to their Burn Unit, Slater, Slater, and Goldfarb (1987) found an overrepresentation of children with single mothers compared to 1980 census data for their referral area. In contrast, Phillips, Mahairas, Hunt, and Pegg (1986), using an Australian sample, found that $87 \%$ of scalds were in children from two-parent homes, and Smith and O’Neill (1984) found that 79\% of the children with burns in their sample from Great Britain had married parents. Interpretation of these latter two studies, however, is limited by the absence of a comparison group.

The relation between race and pediatric burn injuries is equivocal. An analysis of 1,461 fire and burn-related fatalities in children aged 0-19 years revealed that African American and Native American children are more likely to die in a house fire than are Caucasian children (McLoughlin \& McGuire, 1990). Poor children also are more likely to die in a house fire (McLoughlin \& McGuire), and it is not clear whether or not race is associated with house fire deaths after adjusting for poverty. Slater et al. (1987) found an overrepresentation of African 
American children in their sample of children with burns compared to 1980 census data. In contrast, Libber and Stayton (1984) found that the racial distribution (i.e., 70.6\% Caucasian; 29.4\% African American) of their sample of children with burn injuries was not significantly different than that of the population from where their sample came. Unlike race, income consistently has been negatively related to pediatric burns (e.g., El-Badawy \& Mabrouk, 1998; Slater et al.). All children in El-Badawy and Mabrouk’s sample of children with burns were from low-income families; however, the authors note that poverty is pervasive in Cairo from where their sample came. Libber and Stayton found that children with burns had more financial medical assistance due to low income than did comparison children. Similarly, Slater et al. found that the children with burns in their sample were more economically disadvantated than comparison children from 1980 census data.

\section{Parent Health Status}

Psychological. Emotionally unstable mothers in the U.S. have been found to be more likely to have children with injuries than emotionally stable mothers, as measured by a selfreport, temperament scale (Matheny, 1988). This variable remained significant in hierarchical regression analyses controlling for other variables (e.g., mother education and toddler behavior). Vaughan et al. (2004) found that the number of stressful life events reported by a low-income sample of mothers was a significant predictor of mother-reported injuries to young children in hierarchical regression analyses, with greater stress predicting more injuries. In contrast, Dal Santo et al. (2004), using a more financially advantaged sample than that in Vaughan et al., did not find maternal stress to be a significant predictor of mother-reported injuries to young children in the home. Parental substance abuse also has been described as a risk factor for child injury in the U.S (Rivara, 1995). 
Burn researchers (e.g., Kaslow, Koon-Scott, \& Dingle, 1994) have postulated that parental psychopathology may increase children’s burn risk; however, surprisingly, empirical evaluation of this issue is lacking. In a study in Great Britain, Smith and O’Neill (1984) found that one third of burns occur in families with recent emotional upset from a major life event (e.g., birth of a child). Due to the absence of a comparison group, however, it is unclear whether or not this degree of emotional upset also is present in other families.

Libber and Stayton (1984) suggest that parental stress may explain the relation between many sociodemographic variables (e.g., single parenthood) and pediatric burns; yet, parental stress in relation to pediatric burns has been under-investigated. In one U.S. study, no significant difference in self-reported parenting stress was found between parents of children with burns at the time of hospital admission and a normative sample of parents on which the dependent measure was standardized (Blakeney et al., 1993). It is possible, however, that the burn injury minimizes parental perception of pre-burn parenting stress or that parental stress outside of the parenting role, which is not assessed by this dependent measure, is related to child burns. These possibilities, along with the lack of a matched control group, raise caution when interpreting these findings.

Physical. Harel (1988) found that family health problems (e.g., chronic illness) were significantly related to greater child injury risk in the U.S. No research has examined physical health among family members in relation to pediatric burn injuries, specifically.

\section{Parenting Characteristics}

Knowledge of child development and home safety. Eichelberger, Gotschall, Feely, Harstad, and Bowman (1990) conducted a national telephone survey in the U.S. and found that parents of children aged 13 years or younger had little knowledge of safety measures and overly 
relied on vigilance to prevent child injuries. Santer and Stocking (1991) revealed that 50\% of mothers from a financially disadvantaged background had inaccurate knowledge for how to respond to a child poisoning or head injury. Peterson, Mori, and Scissors (1986) found that parents overestimate their and their children's knowledge of safety, and Klein (1980) showed that parents frequently allow their children to do activities (e.g., ambulate in baby walker) that they developmentally are not ready to do. Unfortunately, these studies have not revealed how these problems relate to child injury.

Consistent with the general injury literature, researchers (e.g., Liller, Kent, \& McDermott, 1991) have found that parents err in their knowledge of burn safety specifically. Liller et al. assessed burn safety knowledge of 100 new mothers in the U.S. using a previouslypiloted survey consisting of open-ended and multiple-choice items. An example of an error in knowledge included calling 911 rather than applying cool water as a first response to a burn. This particular error was made by $30 \%$ of the sample (Liller et al.). In a different U.S. study, parents $(N=1,493)$ of young children living in urban, suburban, or rural Massachusetts demonstrated poor knowledge of burn prevention according to a multiple-choice, safety survey (Halperin, Bass, \& Mehta, 1983). On a more fundamental level, parents of young children have been shown to lack knowledge of the likelihood and seriousness of burn injuries compared to other injuries (e.g., choking and falls; Glik, Kronenfeld, \& Jackson, 1993) and underestimate the likelihood of scalds particularly (Eichelberger et al., 1990).

Investigators in burn research have begun to examine safety knowledge in parents of children with burn injuries as well as those without. Rossi et al. (1998) found that guardians of 26 children aged 0 to 12 years who were admitted to a burn unit in Brazil failed to identify dangerous, domestic situations that were responsible for $23 \%$ of the burns in the sample. In a 
sample of 336 Irish children aged 0 to 14 years admitted to a burn unit, Cronin et al. (1996) found that only $70 \%$ of the guardians reported adequate knowledge of first aid for burns. These studies did not compare knowledge deficits among guardians of children with burns to those among guardians of non-burned children, however; thus, it is unclear whether or not the knowledge gaps that were found exceeded those among other caregivers.

Supervision. General injury researchers increasingly are taking interest in the relation between parental supervisory behavior and child injuries. Garling and Garling (1995) found that through supervision, mothers of children aged 1-3 years anticipated on average $61.5 \%$ of possible, near, or actual child injury events that they recorded in a 1-week diary, and prevented injuries in all but a few cases. Interestingly, to prevent injury, these mothers were most likely to physically move their 1-2 year old children away from the hazard or the hazard away from the child, whereas they were more likely to use teaching (e.g., “don’t touch, that's hot!”) with their 3-year old children. Although not detrimental in Garling and Garling's study, this latter type of supervision generally is considered insufficient and risky given that most preschool children are not able to compute, appreciate, and negotiate threats to their safety (Wortel et al., 1994). A lack of parental supervision also has been significantly associated with child injuries, especially for some injuries (e.g., bath drownings; Rivara, 1995). In their retrospective review of injury deaths to young children in two U.S. states over 2 years, Landen, Bauer, and Kohn (2003) identified a problem in caregiver supervision (e.g., inadequate or absent supervision) for $41 \%$ of the fatalities. Recently, Dal Santo et al. (2004) found that greater maternal supervision predicted significantly less home injuries in young children when mothers perceived a low risk of child injury, but not when they perceived a high risk of injury. The authors suggest that maternal 
perception of injury risk may reflect maternal perception of environmental risk, and maternal supervision may be less protective when children are in more hazardous environments.

Child burns specifically have been associated with problematic caretaker supervision (e.g., Carrigan, Heimbach, \& Marvin, 1988). A retrospective review of admissions to a U.S. burn center revealed that $41 \%$ of 81 children (68\% aged 0 to 5 years) had absent or questionable supervision at the time of injury (Carrigan et al., 1988). Libber and Stayton (1984) found that over half of the pediatric bath scalds in their sample occurred with no parent present. A couple of studies in Great Britain found no adult supervision at the time of a burn injury, one study for 27\% of children under 11 years (Smith \& O'Neill, 1984) and one for 21\% of children under 5 years (Green et al, 1984). In Egypt, a guardian was absent at the time of burn for over 37\% of the pediatric, domestic burns (El-Badawy \& Mabrouk, 1998).

\section{Features of the Home Environment}

Housing conditions. Rivara (1995) postulates that one reason for the inverse relation between socioeconomic status (SES) and child injuries is that low-SES families are more likely to live in sub-standard, hazardous housing. In the U.S., Matheny (1988) found more toddler injuries in homes with more noise, disorder, and clutter according to observation by a social worker. This noise-confusion factor remained significant in hierarchical regression (Matheny). Similarly, Mott (1999) found that dark and cluttered homes according to one observer each significantly predicted maternal report of child injuries at home after controlling for other factors (e.g., income) in logistic regression analyses. Dal Santo et al. (2004) identified greater injury risk among young children whose homes needed repair than among those whose homes did not warrant repair. Additionally, crowded home conditions in terms of the number of people per room have been related significantly to increased child injury in the U.S., especially for young 
children (Harel, 1988). Overcrowding also has been related to burn injuries among young children in Egypt (El-Badawy \& Mabrouk, 1998) and Turkey (Turegun et al., 1997).

Number of household members. In the U.S., the presence of more children in the home, irrespective of the number of children per room, has been significantly related to more child injuries (Harel, 1988). The presence of more adults in the home, however, has been related significantly to less child injuries (Harel), perhaps affording greater adult supervision per child. Consistent with the general injury literature, Libber and Stayton(1984) found that overall, U.S. children with burns lived in homes with more children than did children in the 1970 census.

Safety measures and hazards. The general injury literature has investigated safety measures (e.g., presence of smoke detectors) and hazards (e.g., detergents) in the environments of young children without injuries and consistently found both a dearth of safety measures and number of safety hazards worldwide (e.g., Gielen, Wilson, Faden, Wissow, \& Harvilchuck,1995; Greaves, Glik, Kronenfeld, \& Jackson, 1994; Jan, Hasanain, \& Al-Dabbagh, 2000; Kendrick, 1994; Paul, Sanson-Fisher, Redman, \& Carter, 1994). The predominant method of assessment has been self-report using instruments with high face validity. As Wortel et al. (1994) state in their review of parental safety measures, studies generally suggest that parental safety practices are selective and insufficient. The majority of the general injury literature has examined safety devices and hazards in the homes of uninjured children; however, one recent study by Dal Santo et al. (2004) examined home hazards by observation in relation to injuries to young children in the home as recorded by mothers over 1 year. Dal Santo et al. found that greater home hazards were significantly associated with more child injuries when maternal perceptions of risk of hazards were high as opposed to low. The authors suggest that mothers who perceive high risk of hazards may lack motivation or means to decrease home hazards. 
With respect to burn safety practices in the home specifically, Wortel and de Geus (1993) examined burn safety measures taken by 1,129 mothers of preschool children without burns using face-valid questions. Findings revealed that the percent of mothers who behaved unsafely ranged from 7-93\% across burn safety measures. Given the face-valid questions and a general tendency of respondents to present themselves favorably, these results likely are a conservative estimate of true behavior, at best. The burn literature also has begun attending to home safety or lack thereof in relation to pediatric burn injuries. For example, using a Burn Avoidance Index consisting of four, face-valid questions, Petridou et al. (1998) compared the use of kitchen safety measures taken by parents of children with and without burns. Even with the potential social desirability effect on this measure, the authors found that children with burns had a significantly greater percentage of parents who failed to take safety precautions than did control children. Cassell, Hubble, Milling, and Dickson (1997) found that 25\% of the infant burns in their Welsh sample were related to the infant's placement in and use of a baby walker. Forjuoh et al. (1995) found that young children with burns came from homes with significantly more flammable substances than did control children.

\section{Summary and Critique of Prior Research}

In sum, many parental factors have been related significantly and consistently to pediatric burns, including education, income, knowledge of burn prevention and care, supervision, and features of the home. Supervision and some home features have been related to child burns similarly to how they have been related to child injuries in general. More evidence exists in the burn literature than in the general injury literature that income, parental education and knowledge of home safety are related negatively to child injury. The general injury literature, however, has more evidence in support of a negative relation between parental age and child injury than the 
burn literature. Unlike the general injury literature, findings in the burn literature have been mixed regarding parental work and marital status. Findings in the burn literature and the general injury literature have been similarly equivocal regarding the relation between race and injury. Parental health (physical and psychological) has been under-examined in the burn literature compared to the general injury literature. What is perhaps most noteworthy regarding these findings on parental correlates of child burn injuries, however, is that a few variables or some unmeasured variable(s) may account for all of them. With improved methodology (e.g., less confounding variables), a better understanding of those key variables may be achieved.

One strength of the burn and general injury literature is large samples of children from epidemiological studies. An additional, unique strength of the burn literature is international representation. Burn research, however, has not progressed as has the general injury literature regarding the use of multiple methods and attention to parental psychological and physical factors, in particular. Some limitations that beset the burn and general injury literature to varying extents include a(n) (a) dependence on medical charts, (b) over-use of self-report data, (c) reliance on single informants, (d) dearth of (satisfactory) comparison groups, (e) abundance of confounding variables, (f) limited examination of caregiver factors potentially amenable to treatment, and (g) lack of specific analyses for injuries that differ in important ways (e.g., domestic versus non-domestic injuries).

Relying strictly on medical records as a source of family demographic and child injury data is problematic in that medical records often contain inaccurate, inconsistent, and incomplete information. Due to demands placed on heath care professionals and the possibility of human error, medical records may not be valid or comprehensive. Thus, it is important to try to 
corroborate or clarify medical record information, especially when it is suspect or incomplete, by checking it against other sources (e.g., nurses, caregivers).

Many studies in the general injury and burn literature are characterized by one data collection method, usually self-report. Self-report measures, however, are not always valid (Eichelberger et al., 1990; Kazdin, 1998). The likelihood of non-valid responding is compounded by the sensitive nature of variables of interest in the injury literature (e.g., injury occurrence). In the burn literature, self-report methods often are used without ample discussion of their limitations or adequate effort to maximize their utility. For instance, the Burn Avoidance Index used by Petridou et al. (1998) likely yielded some non-valid responding due to social desirability. It might have helped to phrase questions in a less face valid manner. Other recommendations to improve the validity, reliability, and utility of self-report include choosing measures with satisfactory psychometric properties and checking the content validity of new measures. Another idea is to use open-ended self-report measures (e.g., of safety knowledge) so that the "right" answer is not evident. Researchers also should strive to utilize multiple methods (e.g., observation, standardized measures with validity scales) to address some of the biases of selfreports and supplement methods involving retrospective recall.

Studies in the general injury and the burn literature also have relied on single informants. Under-utilized informants include fathers and grandparents. When available, the use of multiple informants for some information (e.g., who was present at the time of the injury) would help address the potential biases of one informant and enable confirmation of reported events.

A number of studies in the general injury and burn literature failed to include a comparison group. More common in burn research than in the general injury literature is the use 
of non-matched comparison groups. For example, Blakeney et al. (1993) used a normative group for comparison, which was not matched to the relevant sample.

An impediment to interpreting relations between variables in the general injury and burn literatures is the presence of confounds, such as that between race and income in the analysis by McLoughlin and McGuire (1990). Some researchers (e.g., Matheny, 1988) ran hierarchical regressions to adjust for confounds. It is recommended that researchers routinely take such steps. Researchers also should strive to recruit larger, heterogeneous samples when possible so that confounds can be covaried out while retaining sufficient variability and power. Covarying out confounds is crucial to understanding exactly who is at risk and who to target for intervention.

Many studies in the general injury literature and particularly the burn literature are characterized by a restricted examination of parental demographic variables as opposed to factors that can be modified with treatment. Parent behaviors (e.g., supervision) in particular have been under-researched in the injury literature (Kronenfeld \& Glik, 1995; Saldana \& Peterson, 1998). Greater investigation of parental psychological/behavioral factors that may be altered with intervention is needed.

General injury researchers frequently collapsed injuries of different type, severity, and setting into one analysis. The importance of looking at different types of childhood injuries separately is being recognized increasingly by general injury researchers (e.g., Morrongiello \& Kiriakou, 2004). Likewise, the burn literature lacks separate analyses for domestic versus nondomestic burns and for children of different ages. Greater separation of pediatric burns in the aforementioned ways would help researchers understand parental factors related to burns in children who are more or less influenced by characteristics of the home and of different ages. Smith and O’Neill (1984) separately examined children with burns in two different age groups; 
however, the dividing year that they used (i.e., 10 years) seems illogical given what is known about types of burns sustained by children at different ages. For example, children aged $0-5$ years are more likely than older children to be burned in the home (Tarnowski, 1994) and to be scalded (Chedekel et al., 1998); thus age 5 years might be a more appropriate cutoff.

$$
\text { Purpose of the Present Study }
$$

\section{Primary Aim}

The primary aim of the present study was to examine whether or not primary caregivers of young children with burn injuries are significantly different in certain psychological/ behavioral areas (i.e., home safety knowledge, home safety behaviors, parenting stress, and psychopathology), all of which potentially are amenable to treatment, from primary caregivers of similar children without burn injuries. In other words, the author was interested in whether or not certain caregiver psychological/behavioral problems (e.g., poor knowledge of home safety) significantly predict the occurrence of a burn injury in a young child above and beyond family demographic factors as a first step toward identifying parental factors that may have an influential role in early childhood burns.

Based on prior research and clinical experience, the author expected that correlational analyses would reveal a significant, negative association between the occurrence of a child burn injury and both caregiver knowledge of home safety and safety practices (i.e., supervision and home hazard control). Although prior research on parenting stress and parental psychopathology in relation to child injury including burns is especially limited, the author hypothesized that parenting stress and caregiver psychopathology each would be significantly and positively related to the occurrence of a pediatric burn injury. Blakeney et al. (1993) did not find significant differences in parenting stress between parents of children with burns and those of children 
without burns; however, unlike the present study, they did not use an appropriate comparison group. Also, due to an absence of age information, it is not clear whether or not the children with burns examined by Blakeney et al. were young children, who place unique demands (e.g., the need for close supervision and assistance) on parents, as in the present study. Lastly, based on prior research, the author expected that some family demographic variables would be significantly related to child burn injury occurrence. In particular, it was hypothesized that the number of adults in the home, age and education of the primary caregiver, and family financial status would be significantly, negatively associated with a child burn injury, whereas the number of children in the home, the frequency of older siblings providing care for young children, and the number of hours of care-giving by non-primary caregivers would be significantly, positively related to a child burn injury. A restricted number of other family demographic variables (e.g., work status of the main other caregiver, number of household smokers) also were considered relevant and explored in correlational analyses without any apriori hypotheses due to a lack of prior research.

In a discriminant function analysis, with caregiver psychological/behavioral and family demographic variables entered as predictors and pediatric burn injury occurrence entered as a dichotomous outcome variable, the author predicted, based on existing research and clinical experience, that caregiver safety knowledge and behavior would discriminate between caregivers of young children with burns and caregivers of young children without burns above and beyond variance predicted by parenting stress, parental psychopathology, and family demographic characteristics. Secondarily, it was anticipated that parenting stress and parental psychopathology each would significantly predict the presence of a childhood burn injury after accounting for the prediction by relevant demographic variables. 


\section{Secondary Aim}

A secondary aim of the present study, related to the primary aim, was to examine whether or not certain caregiver psychological/behavioral variables significantly predict caregiver safety practice (i.e., supervision and home hazard control) as a step toward identifying caregiver factors that may influence behavior that protects children against burn injuries. The author was interested in evaluating whether or not these psychological/behavioral variables predict caregiver safety behaviors above and beyond relevant family demographic characteristics, such as ones that have been associated with pediatric burns, other child injuries, or caregiver safety practices.

In correlational analyses, it was expected that caregiver psychological/behavioral variables and family demographic variables would relate to caregiver safety behavior in the opposite direction in which they were hypothesized to relate to child burn injury occurrence given that in theory, safety behavior is contrary to injury occurrence. In hierarchical regression analyses, with caregiver psychological/behavioral and family demographic variables entered as predictors, and home safety behavior entered as a continuous outcome variable, the author expected that home safety knowledge would account for a significant amount of variance in caregiver safety practices after accounting for parenting stress, caregiver psychopathology, and family demographic factors. Finally, it was expected that parenting stress and caregiver psychopathology each would predict a significant portion of variance in safety practices above and beyond variance accounted for by demographic variables. 


\section{Method}

\section{Participants}

Participants consisted of 60 primary caregivers, 30 of whom had a child age 5 years or younger with a new burn injury (i.e., open wound) severe enough to warrant medical attention (case participants), and 30 of whom had a child who had not experienced a burn injury (comparison participants). The primary caregiver was defined as the caregiver who spends the most amount of time with the target child in the child's home. The two groups of participants were balanced for the child’s age, gender, race, and geographic region, as well as the primary caregiver's SES and marital status (Table 1). For the purpose of balancing groups, SES was defined as the use or non-use of public financial assistance, and marital status was defined as single, married, or other (e.g., living with partner).

Case participants. Case participants were recruited from a burn unit (BU; inpatient) and associated burn care office (outpatient) at an urban hospital in the Northeastern (NE) U.S. Three inclusion criteria were used: (a) The patient had to be age 5 years or younger, (b) the patient had to live within a 3-hour driving distance from the hospital or the author's residence, and (c) the primary caregiver had to be literate enough to complete the standardized questionnaires used in the present study. One case participant was excluded on the basis of living too far away.

When approached or contacted for participation, case participants were told that the purpose of the study was to examine primary caregivers of young children (some with burn injuries and some without) and better understand their resources (e.g., financial, educational, safety knowledge), stress levels as parents, and psychological well-being. Participants also were told that the study aims to determine whether or not there are some areas (e.g., home safety 
information) in which caregivers of young children with burn injuries in particular might benefit from more support, information, or guidance.

Of all potential case participants approached for participation, 16 (31\%) refused to participate. Reasons for refusing included no time to participate $(n=3)$, not wanting to answer personal questions $(n=2)$, not wanting to talk about or “relive” the burn injury $(n=2)$, disinterest in research $(n=2)$, too stressed $(n=1)$, disinterest based on having "mastered home safety” ( $n=1)$, disinterest due to the belief that injuries cannot be prevented $(n=1)$, and family member disliking strangers in the home $(n=1)$. The author was unable to determine reasons for refusing from three individuals who declined to participate. Of those cases who said they would participate, 5 (14\%) dropped out prior to completing the study. Reasons for dropping out were no time due to a change in work schedule ( $n=1)$, sudden illness in the family $(n=1)$, or sudden need to change residence $(n=1)$. The PI was unable to ascertain reasons for dropping out from two individuals who could not be reached by numerous telephone calls or letter after having consented into the study. Two independent samples t-tests were conducted to compare case participants to those potential cases who did not participate (i.e., refused participation or withdrew from the study) on (a) child age and (b) percent total body surface area (TBSA) of the burn. The age (in months) of children of case participants $(M=26.40, S D=14.76)$ was not significantly different from the age of non-participating children of potential case participants $[M$ $=24.00, S D=15.74 ; t(49)=.56, p=.58]$. Similarly, the percent TBSA of the burn among the case group $(M=5.50, S D=6.59)$ was not significantly different from that among the group who declined participation or withdrew from the study $[M=4.35, S D=6.74 ; t(48)=.60, p=.55]$. The final sample of case participants consisted of 27 (90\%) mothers, 2 (6.7\%) grandmothers, and 1 (3.3\%) father. The ages of these primary caregivers ranged from 20 to 43 
years $(M=30.17, S D=6.47)$. Sixty percent of these participants received greater than a high school education, whereas $40 \%$ did not. Thirty percent of case participants were unemployed, $30 \%$ were employed part-time, and $40 \%$ were employed full-time. Annual household income ranged from less than $\$ 15,000$ to $\$ 75,000$ or greater, with $26.7 \%$ of cases making $\$ 45,000$ or greater, and $73.3 \%$ of cases making $\$ 44,999$ or less. The most common income bracket of case participants was $\$ 35,000-\$ 44,999$ (23.3\%). All case participants gave informed consent to participate.

Comparison participants. Comparison participants were recruited from multiple settings based on the geographical make-up of case participants. The different settings included a pediatric practice in the same city as the BU to represent children from an urban setting, a pediatric practice in a NE U.S. town to represent rural children, and rural sites in the NE U.S. where the BU Outreach Coordinator (BUOC) lectures on various topics. Comparison participants were excluded if they had primary care for any child who sustained a burn injury requiring medical attention or if they did not have the reading proficiency to complete the standardized questionnaires in the present study. Two comparison participants were excluded from participation due to having a child with a previous burn injury requiring medical attention. Based on descriptive statistics of children aged 5 years and under who were treated for burn injuries at the BU between July 1, 2000 and June 30, 2001, initially, 25\% of recruitment honed on the urban site, whereas $75 \%$ of recruitment centered on the rural sites. Participants were recruited directly when waiting for clinic appointments or via telephone contact after having received a recruitment flyer that solicited family contact information from potentially interested participants. After about 75\% of the comparison participants were enrolled, the group was evaluated for equivalence to case participants in terms of child age, gender, race, and 
geographical location, as well as caregiver SES and marital status. Equivalence on balanced variables was largely satisfactory at this time; however, for the last $25 \%$ of the participants, recruitment of comparison participants prioritized single caregivers over married or romantically-involved ones, and families of lower SES to make the groups more similar.

Six (16\%) comparison participants who were approached for participation refused to participate. Reasons for declining included no time $(n=3)$, not interested $(n=1)$, and belief that questionnaires are invasive $(n=1)$. One participant would not state her reason for refusing. No comparison participants who consented to participate dropped out of the study. An independent samples t-test revealed no significant difference when comparing the child age (in months) of comparison participants $(M=24.60, S D=16.70)$ to potential comparison participants who declined to participate $[M=17.33, S D=14.83 ; t(34)=.99, p=.33]$.

The final sample of comparison participants consisted of $100 \%$ mothers. The ages of these caregivers ranged from 20 to 42 years $(M=29.57, S D=5.89)$. Comparison participants who received greater than a high school education made up $73.3 \%$ of the comparison group, whereas those who received a high school education or less comprised $26.7 \%$ of this group. The employment break down of comparison participants was $46.7 \%$ unemployed, $23.3 \%$ employed part-time, and 30\% employed full-time. Annual household income ranged from less than $\$ 15,000$ to $\$ 75,000$ or greater, with $44.8 \%$ of comparisons making $\$ 45,000$ or greater, and $55.2 \%$ of comparisons making $\$ 44,999$ or less. The most common income bracket of comparison participants was less than $\$ 15,000$ (26.7\%). All comparison participants gave informed consent. 
Measures

Demographic Questionnaire (Appendix A). The Demographic Questionnaire was used to gather family and child information relevant to the purposes of the study. For relevant data analyses, an aggregate financial variable was made by summing the annual household income bracket (with higher values assigned to lower income brackets), number of public financial assistance programs, and child insurance rating (i.e., "Medicaid" or no insurance $=1$; "NonMedicaid” =0). Regarding hours of care-giving by non-primary caregivers in the home, an aggregate variable summing care-giving hours per week by each non-primary caregiver in the home was used in relevant data analyses. A similar aggregate variable was created for hours of care-giving by non-primary caregivers out of the home.

Burn Information Form (Appendix B). The Burn Information Form (BIF) was used to gather specific information about the pediatric patient's burn injury. Some of this information (e.g., persons present at the time of the burn incident) was obtained from a brief interview with the primary caregiver and another caregiver separately, if present, for confirmation purposes (Part 1). Other information was gathered via medical chart review and confirmation from health care staff whenever possible (Part 2). Variables on the BIF were extracted for descriptive analysis (e.g., averages and standard deviation).

The Personality Assessment Inventory (PAI; Morey, 1991). The PAI is a 344-item, selfreport measure of general adult psychopathology. The instrument has a fourth grade reading level and takes approximately 45-60 minutes to complete. The PAI has recent U.S. normative information and good psychometric properties. Using a census-matched normative sample of community-dwelling adults $(N=1000)$ across rural and urban areas of the U.S., internal reliability coefficients (Cronbach’s alpha) ranged from .72-.90 across the different PAI scales 
(Morey). Among a similar sample $(N=75)$, test-retest reliability coefficients ranged from .71-.94 across the PAI scales, with a retest interval of 24 days (Morey). Validity studies using samples of community-dwelling adults reveal correlation coefficients of .5 or greater between the majority of PAI scales and similar scales on other measures of personality and psychopathology (Morey). The PAI contains 22 non-overlapping scales broken down as follows: 11 clinical scales (i.e., somatic complaints, depression, anxiety, anxiety-related disorders, mania, paranoia, schizophrenia, borderline features, alcohol problems, drug problems, and antisocial features), 5 treatment scales (i.e., aggression, suicide ideation, general stress, nonsupport, and treatment rejection), 2 interpersonal scales (i.e., dominance and warmth), and 4 validity scales (i.e., inconsistency, infrequency, negative impression, and positive impression). The treatment scales, unique to the PAI, tap important treatment considerations including how likely the informant is to respond to mental health treatment. The respondent answers each item of the PAI by circling one of four choices ranging from "false” to "very true."

The PAI yields a gender-based T-score $(M=50, S D=10)$ for each of the 22 scales. Tscores greater than or equal to 70 are considered clinically significant. Scores can be interpreted in relation to both normal and clinical samples. For the purpose of this study, participant scores on the PAI were interpreted in relation to a normal sample of adults. For relevant data analyses, the author extracted from the PAI the total number of clinically significant scales (i.e., scales with a T-score $\geq 70$ ) from the 11 clinical, 5 treatment, and 2 interpersonal scales provided that the respondent answered items in a valid manner according to the 4 validity scales. PAI results for participants who did not respond in a valid manner were not entered in relevant data analyses; however, the number of non-valid responders is reported descriptively. The author also performed a descriptive analysis of the type of clinically significant clinical, treatment, and 
interpersonal scales associated with both groups of caregivers in the present study. Independent samples t-tests were conducted to evaluate group differences.

The Parenting Stress Index-Short Form (PSI-SF; Abidin, 1995). The PSI-SF is a direct derivative of the full length PSI. All items on the short form also are contained on the long form. The PSI-SF is a self-report assessment measure of parental stress, specifically surrounding parenting, with normative information and satisfactory psychometric properties. Cronbach’s alpha for the Total Stress Score on the PSI-SF was .91 among a normative sample of mothers ( $N$ $=800$ ) comparable to participants in the present sample (Abidin). Among an analogous sample $(N=270)$, test-retest reliability for the Total Stress Score was .84 across a 6-month retest interval (Abidin). Validity studies with the PSI-SF have been limited; however, the PSI-SF Total Stress Score correlated .94 with the Total Stress Score on the full-length PSI using a normative sample of 530 mothers (Abidin). Furthermore, the Total Stress Score of the full-length PSI has been significantly correlated with scores on a number of relevant measures, such as the Family Resource Scale and the Child Behavior Scale, using other samples of mothers of young children. The PSI-SF examines the three factors of Maternal Esteem, Parent-Child Interaction, and Child Self-Regulation, as different facets of the parent-child system and as potential contributors to parenting stress. It consists of 36 questions, which take approximately 10 minutes to complete. The respondent answers each item by circling one of five choices ranging from "strongly agree” to “strongly disagree.” For a small subset of questions, respondents are given five written statements as choices and asked to choose one.

The PSI-SF provides three subscale scores labeled Parental Distress, Parent-Child Dysfunctional Interaction, and Difficult Child. The questionnaire also yields a validity measure, the Defensive Responding Score. A Total Stress score is obtained by summing scores from the 
three subscales. It represents total stress in the parenting role alone; not necessarily the total amount of stress a parent is experiencing. A Total Stress raw score above 90, or at or above the 90th percentile, is considered clinically significant. Total raw scores were used in relevant data analyses; however, descriptive information regarding total and subscale percentile scores is provided for interpretive purposes.

The Primary Caregiver Supervisory Index (PCSI; Appendix C). The PCSI, based directly upon the Maternal Supervisory Index (MSI; Greaves et al., 1994), is a self-report measure of parental safety practice with respect to supervision (i.e., level of permissiveness versus protectiveness) in various, hypothetical scenarios, each with a risk of at least one type of child injury (e.g., burn, fall, drowning). The PCSI includes the same instructions, items, response format, and coding procedures as the MSI with the only differences being minor wording changes to 8 of the 11 original items on the MSI and the addition of 7 items representing burn risk specifically. Wording changes were made to some original items to increase their clarity and conciseness and/or make them more widely-applicable to any aged child in the present study as well as both female and male caregivers. The additional items of the PCSI were deemed necessary for the purposes of the present study, because only 2 of the 11 items on the MSI represent pointedly child burn injury risk. Nonetheless, because the MSI makes up a good part of the PCSI, and the novel items on the PCSI were developed, administered, and scored in the same manner as those on the MSI, the MSI is described below.

Each of the 11 items of the MSI consists of a brief vignette that presents a common child safety risk situation to parents and asks them what they would do in the situation. The MSI is delivered as an interview and uses an open-response format, the former ensuring adequate item comprehension and completion, and the latter keeping responses that reflect good parental 
supervision non-apparent. Responses on the MSI are recorded and later categorized into four operationally-defined levels of cautiousness (i.e., supervision). Coding procedures for the MSI are as follows: An item score of " 4 ” is given to responses in which the respondent removes the hazard (e.g., matches) or the child from the hazard; an item score of " 3 " is designated when the respondent provides closer, physical supervision of the child; an item score of "2" is given to responses in which the respondent provides only verbal instruction to the child; and an item score of " 1 " is assigned if no supervision of any sort is provided.

The seven items of the PCSI that were developed for the purpose of this study (i.e., items $3,5,9,11,14,16$, and 18) were created to tap common burn risk scenarios for young children. Originally, the author asked three experts in pediatric burn care and prevention (i.e., professionals who work in burn care and prevention and have specialized knowledge in these areas) to check five, newly-developed, burn items for clarity of wording and adequate representation of common burn risk situations for young children (i.e., content validity). These items were modified according to majority rule while retaining the format of items on the MSI. One expert reviewer also recommended the addition of two items (i.e., items 5 and 11) to increase the representation of common burn scenarios for young children. A Flesh Kincaid reading level analysis of all 18 items on the PCSI revealed a grade level of 5.8.

Three scores were derived from the PCSI: (a) an Overall Supervision Score obtained by averaging all individual item scores, (b) a Burn Supervision Subscale Score obtained by averaging all burn-related items, and (c) a Non-Burn Supervision Subscale Score obtained by averaging all non-burn-related items. Items that apply to burns and other types of injury (e.g., bathing items) were factored into both the Burn and Non-Burn Subscale Scores. For all three scores, higher scores reflect better parental supervision. 
The PI trained an undergraduate research assistant (RA) in PCSI scoring procedures initially using didactic methods and sample PCSI responses. Subsequently, the PI administered the PCSI to five pilot caregivers of a young child for evaluation of inter-rater agreement. The author and RA did not achieve satisfactory inter-coder agreement (i.e., percent agreement $\geq .80$ ), on the first set of five pilot questionnaires. After reviewing where they drifted in their coding, and creating scoring guidelines for responses that were difficult to code using the general coding procedures of the MSI (Appendix D), however, they achieved an average of 97\% agreement across all items of the PCSI on their second set of five pilot questionnaires, with percent agreement no less than $89 \%$ on any one questionnaire. Once they had achieved satisfactory intercoder agreement on the Overall Supervision Score with pilot families, they independently scored 20\% of completed PCSIs in the present study. Average percent agreement for the Overall Supervision Score was 94\%, with agreement levels remaining above $80 \%$ for each evaluation. Still, the author and RA continued to discuss where their scoring diverged over the course of the study to stay reliable. At the end of the study, the author calculated inter-coder agreement for each individual item on the PCSI. Only one individual item (i.e., item 8) had unsatisfactory (< .80) agreement. This item was excluded from Overall Supervision Score calculations.

Before any PCSI scores were used in relevant data analyses, the internal consistency of the measure (i.e., 17 items with satisfactory inter-coder agreement) was determined using Cronbach's alpha. Due to unsatisfactory internal reliability ( $\alpha=.27$ ), items whose deletions resulted in improvements in alpha were removed sequentially. Cronbach’s alpha was recalculated following these item deletions and found to be .55 with a resulting 7 -item measure. On the original, 11-item MSI, Greaves et al. (1994) reported a similar alpha reliability coefficient of .58 using a sample of 230 mothers. More recently, Dal Santo et al. (2004) reported an alpha 
value of .57 for the internal consistency of this measure with a sample of 159 mothers. In relevant data analyses for the present study, PCSI Overall Supervision Scores were used due to both the small number of items contributing to the overall score and a significant, positive correlation between the two subscale scores of the PCSI, $r=.77, N=60, p<.01$. In cases in which two coders scored a single PCSI, the author's PCSI scores were used in relevant data analyses due to the author having more clinical and research experience in injury prevention than the RA.

The Home Safety Knowledge Interview (HSKI; Appendix E). The HSKI, based predominantly upon a home safety questionnaire developed by Morrongiello, Midgett, and Shields (2001), is a 29-item interview of parental knowledge of home safety measures for 29 different injury risk situations. The home safety questionnaire in Morrongiello et al. assessed (a) home safety instructions or rules that parents had for their pre-school aged children in 33 situations containing child injury risk (e.g., parents cooking on top of a stove) using an openended format, (b) how compliant children were with the safety rules using a 5-point Likert scale, and (c) parental reasons for not having safety rules using a forced-choice format. Morrongiello et al. developed their items of child injury risk scenarios (e.g., running in the house) through an extensive review of the literature on home safety issues for young children and a pilot study with 21 parents.

From the home safety questionnaire developed by Morrongiello et al. (2001), the author has retained their open-response format, so that the "correct answer" is not evident, and most child burn and non-burn injury risk situations, with those injury risk situations that the author retained indicated with an astrix in Appendix E. In addition to including many risk situations identified by Morrongiello et al., the HSKI includes pediatric burn and non-burn injury risk 
situations identified by other researchers (e.g., Harre, Field, \& Polzer-Debruyne, 1998; Liller et al., 1991; Petridou et al., 1998; Rossi et al., 1998; Varas, Carbone, \& Hammond, 1988; Wortel \& de Geus, 1993) and used in other published measures of child safety (e.g., the Post-Partum Patients’ Knowledge, Risk Perceptions, and Behaviors Pertaining to Childhood Injuries Survey; Liller et al.). Another distinction about the HSKI relative to Morrongiello et al.'s safety measure is that it only assesses safety measures (e.g., rules and steps) known by primary caregivers, not child compliance to parental home safety rules or parental reasons for not having them.

Due to a number of differences between the HSKI and the home safety measure created by Morrongiello et al. (2001), the author recruited 3 experts in the injury prevention field, as previously defined, to review the HSKI (28 items originally) for clarity and content validity. Items were modified according to majority vote. One expert reviewer also recommended the addition of one item (i.e., item 29). The author performed a Flesh Kincaid reading level analysis of the final measure, which revealed a grade reading level of 4.8 .

Scoring for the home safety measure developed by Morrongiello et al. (2001) focused on the number of child injury risk situations for which a parent had a safety rule for the child, not whether or not the safety rule is considered to be good safety practice (e.g., turning pot handles inward on a stove; Varas et al., 1988). Consequently, the author developed different scoring procedures for the HSKI. On the HSKI, each item is scored in terms of the safety measure(s) reported for the situation. The respondent's safety knowledge was coded as poor (score of “1”), fair (score of “2”) or good (score of “3”). A "good” response is one in which the caregiver reports a safety measure(s) that reduces the injury risk as much as possible (e.g., using a safety gate to keep young children out of the kitchen when cooking after engaging them in a safe activity in the next room), a "fair” response is one in which the caregiver reports a safety 
measure(s) that lessens the injury risk but not as much as possible (e.g., telling the child to stay away from the stove when cooking in the kitchen), and a "poor” response is one in which the caregiver states no knowledge of a safety measure for the situation or reports a safety measure that does not lessen the injury risk at all (e.g., trusting that the child will stay away from the stove because it makes common sense to do so). From the HSKI, an Overall Safety Knowledge Score, derived by averaging all individual item scores, and two Safety Knowledge Subscale Scores, one for burn-related items and one for non-burn related items, were obtained. Items that apply to burns and other types of injury were included into both subscale scores. Higher scores reflect better safety knowledge.

The author trained the same RA who helped code PCSI questionnaires in HSKI scoring procedures using methods (e.g., didactic teaching, coding samples) described previously. Didactic teaching focused on good home safety responses for each item (Appendix F). The author and RA did not achieve satisfactory inter-coder agreement (i.e., percent agreement $\geq .80$ ), on the first set of five pilot questionnaires; however, after reviewing scoring discrepancies on the first set, they achieved an average of 92\% agreement across all items of the HSKI on a second set of five pilot questionnaires. Percent agreement was no less than $86 \%$ on any one pilot questionnaire in the second set. Once they achieved satisfactory inter-coder agreement with pilot families, the author and RA independently scored the same 12 (20\%) HSKIs in the present study. The author calculated inter-coder agreement on the Overall Safety Knowledge Score throughout the study to check for coder drift. Percent agreement did not drop below $80 \%$ at any point; however, the author and RA discussed where their scoring diverged throughout the study to remain reliable. Across the 12 HSKIs that the author and the RA independently scored, they averaged 91\% agreement on the Overall Safety Knowledge Score. At the end of the study, the 
author calculated inter-coder agreement for each individual item on the HSKI. Four individual items (i.e., items 11, 16, 18, and 22) had unsatisfactory agreement and therefore were excluded from Overall Safety Knowledge Score calculations.

Before any HSKI scores were used in relevant data analyses, the internal consistency of the measure (i.e., 25 items with satisfactory inter-coder agreement) was determined using Cronbach’s alpha. Due to unsatisfactory internal reliability $(\alpha=.59)$, items whose deletions resulted in improvements in alpha were removed sequentially. Cronbach’s alpha was recalculated following these item deletions and found to be .65 with the resulting 20 -item measure. In relevant data analyses, HSKI Overall Safety Knowledge Scores were used, because the two subscale scores (burn and non-burn) were significantly correlated, $r=.72, N=60, p<$ .01. In cases in which two coders scored a single HSKI, the author's scores were used in relevant data analyses for reasons previously described with respect to the PCSI.

Observed Home Safety Measures (OHSM; Appendix G). The OHSM is a 26-item, observational measure of home safety measures and hazards developed for the purpose of this study. Part 1 assesses the presence versus absence of 18 different safety devices (e.g., electrical outlet plugs) or hazards (e.g., baby walkers), with a "NA" for "not able to determine” or "not applicable” option also available. These safety devices and hazards were chosen based upon an extensive review of the early childhood injury literature with relatively more weight placed on safety measures pertaining to pediatric burn injuries. Part 2 assesses whether the accessibility of various items (e.g., matches/lighters) and temperature setting of the hot water tank is "safe” (i.e., no child injury risk or maximal reduction of child injury risk) or "unsafe” (i.e., child injury risk that has not been reduced as much as possible) with the same "NA" option described for Part 1. Like Part 1 items, items in Part 2 were developed via a review of the literature. Item 
development also stemmed from the (a) home hazards that contributed to many early childhood burns at the BU and (b) burn safety education materials that BU staff give to caregivers of young children who have been burned.

Because the OHSM was developed for the purpose of the present study, the author recruited 3 experts in the injury prevention field, as defined earlier, to review the measure for clarity and content validity. The original measure was modified according to majority opinion and two items were added as suggested by one reviewer.

In terms of scoring, item responses that reflect poor home safety behavior were given a score of " 0 ” whereas item responses that reflect good home safety behavior were scored as " 1 .” An Overall Safety Measures Score was derived by averaging all item scores, and Burn and NonBurn Safety Measures Subscale Scores were derived by averaging relevant items as discussed with the PCSI and the HSKI. Higher scores reflect better home safety practice.

The PI trained two undergraduate and two graduate RAs in OHSM scoring procedures. For each RA, training was didactic (e.g., reviewing scoring for various hypothetical scenarios; Appendix H) and involved pictures of various home safety devices (e.g., stove guards) and hazards to help familiarize researchers with the appearance and common locations of such devices and hazards. Inter-observer agreement on the OHSM was checked prior to data collection by having the PI and each RA complete the OHSM in 3 homes of non-participants who are primary caregivers for at least one young child. With pilot families, mean kappa statistics of inter-observer agreeement between the author and each of the four RAS were .82, $.87, .88$, and .93. Once satisfactory inter-observer agreement was established on the Overall Safety Measures Score, the OHSM was completed in participant homes. Both the PI and a reliable research assistant independently completed the OHSM in the same home for 12 (20\%) 
participants. Inter-observer agreement did not drop below a $k$ value of .75 at any point during data collection; however, reliability coders reviewed scoring differences throughout the study to re-establish consensus for future OHSM scoring. Across the 12 OHSM questionnaires, the average $k$ value across all items was .89. Five items (i.e., items 7, 15, 17, 20, and 24) were deleted due to unsatisfactory inter-observer agreement (i.e., $k<.75$ ) and excluded from OHSM score calculations.

The internal consistency of the OHSM (i.e., 21 items with satisfactory inter-coder agreement) was checked using Cronbach’s alpha. Because 59 of the 60 participants had at least one "NA" item rating across all items on the OHSM, and "NA" ratings were entered as missing data, the internal consistency of this measure could not be evaluated due to "too few cases.” In order to evaluate the internal consistency of the OHSM, the author deleted 5 items with a preponderance of missing data across participants (i.e., approximately one third or more of the participants got an "NA" rating for that item). These items were 9, 10, 18, 25, and 26, and in almost all cases, the "NA" rating was because the item (e.g., stairs, fireplace, plugged-in space heater) was not present in the home. After deleting the aforementioned 5 items, all participants had 0-2 missing item values across the OHSM. For each participant who had 1-2 missing item values (as opposed to none), the author replaced the missing data values with the participant's average item score across the remaining OHSM items that had data values. Subsequently, the author conducted an internal consistency analysis on the 16-item OHSM and obtained an alpha value of .63 $(N=60)$. One item was deleted to increase the measure's overall internal consistency to a satisfactory value ( $\alpha=$.69). In relevant data analyses, OHSM Overall Safety Measures Scores were used, because the two subscale scores (burn and non-burn) were significantly correlated, $r=.71, N=60, p<.01$. When the author and an RA were in the home, 
the author's OHSM scores were used in relevant data analyses for reasons previously stated with regard to the PCSI and the HSKI. For a minority of cases in which the author was not one of the two reliability observers in the home, the graduate reliability observer's OHSM scores were used in relevant data analyses due to the graduate observer having more advanced research training overall than the undergraduate observer.

\section{Procedure}

When participants were enrolled in the study in-person (as opposed to over the telephone), the recruiting researcher administered the Demographic Questionnaire, the PAI, and the PSI-SF at the site of enrollment to lessen the duration of the home visit. A pre-addressed, pre-stamped envelope was provided to participants who could not, for some reason (e.g., time restraints), complete these forms at the site of enrollment. Procedures were similar for participants who gave informed verbal consent to participate in the study over the phone, except for the fact that the instructions for completing the questionnaires were explained by the author over the phone and the questionnaires were mailed to participants, along with research consent forms. The author also included an explanatory cover letter with the mailing of questionnaires, which included a number where the author could be contacted should the participant have questions. All participants were encouraged to complete the measures as soon as possible and return them in the envelope provided. The author generally called participants 1-2 weeks following enrollment to prompt them to return these forms before they got lost or, if their home visit was scheduled soon, to keep the forms so that they could be collected at the home visit.

At the BU enrollment site, the researcher also administered Part 1 of the BIF as an interview. For case participants who were enrolled over the phone, Part 1 of the BIF was completed at the home visit. When more than one caregiver was present and willing, the author 
conducted Part 1 of the BIF with each caregiver independently to obtain two informants of potentially sensitive information. In these cases, only data that was described consistently by both informants were used in relevant data analyses. Unfortunately, there were few instances when two caregivers were present for interviewing, had information about the burn incident, and were willing to describe the burn incident separately. Caregivers from a few participating families refused to be interviewed separately, claiming that they had the same information to share or one of the caregivers was the better informant (e.g., based on having been present at the time of injury). Consequently, the majority of all data from Part 1 of the BIF came from one informant (i.e., the primary caregiver).

Other information on the BIF (e.g., TBSA) was obtained through a medical chart review. The process was not completed until written consent was obtained and after the child was discharged from the hospital (when relevant) to make sure that all information of interest (e.g., complications during hospitalization) was obtained. Whenever possible, information derived from patient medical charts was verified by a burn care provider (e.g., physician or nurse) given potential problems with medical record data (e.g., inconsistent and incomplete information).

At the time of enrollment, the recruiting researcher scheduled a 1-2 hour home visit no later than one month after the time of enrollment. For case participants, the researcher attempted to schedule the home visit as close to the time of the burn injury as possible to lessen the amount of time between pre-burn parental status (e.g., knowledge) and assessment of this status. At the same time, the researcher was sensitive to elevated distress levels of case participants and tried to schedule the home visit when these levels began to subside. Unfortunately, for a small minority of participants from each group, the home visit actually occurred 5-8 weeks after the time of enrollment, due to families failing to keep their original home visit date. Psychology and Child 
Life staff at the BU were instructed not to educate case participants about burn prevention and care until the end of the home visit to prevent an inflation of pre-burn safety knowledge among these participants. Case participants received burn prevention education that typically is disseminated by psychology and/or child life staff at the BU or associated outpatient facility at the end of study participation, through the graduate researcher at the home visit. Participants were told that the reason for going to the home was to collect data in a comfortable setting at a convenient time for the family as well as better appreciate features of the home that may create challenges for home safety. Other reasons for collecting data on safety knowledge and behavior in the home were to (a) decrease the likely tendency of participants to respond in a socially desirable manner when surrounded by their child's health care providers or other caregivers and (b) observe home safety measures. For $20 \%$ of the home visits, two researchers were in attendance for inter-observer agreement purposes. Home visits with two researchers present were distributed equally across groups.

At the home visit, the author or another graduate researcher administered the PCSI followed by the HSKI. Then, the researcher(s) completed the OHSM going through the home with the primary caregiver. When two researchers were in the home, they completed the OHSM independently. The researcher(s) did not inform participants of item responses on the OHSM unless they were requested.

At the end of the home visit, participants were paid \$30, their names were entered into a lottery for one \$100 gift, and they were provided with correct answers on the HSKI and encouraged to ask questions about home safety or the study in general. The researcher(s) distributed small toys to young children in the home. Finally, the researcher told participants that an appropriate referral could be provided upon request if the caregiver had any concerns after 
completing the PAI and the PSI-SF or any other aspect of the study. Any participant who endorsed suicide items on the PAI was screened for suicidal intent or plan. Fortunately, no participant endorsed more than suicidal ideation; thus, the author's interventions consisted of feedback and, for two participants, providing an appropriate referral as deemed necessary. Although a number of families lived in poor housing conditions, had limited resources, and/or demonstrated a lack of effective parenting skills (e.g., ability to manage their children’s behavior), there were no instances in which the author or another graduate researcher suspected and, in turn, was obligated to report child abuse or neglect, as mandated by ethical principles for psychologists. 
Results

\section{Sample Characteristics}

Burn injury data. Descriptive statistics were calculated to describe the sub-sample of children with burns in terms of the characteristics of their burn injuries. Types of burn injuries consisted of scalds (50\%); hot object contact burns, such as contact with a curling iron or stove (33.3\%); steam burns (6.7\%); flame burns (6.7\%); and grease burns (3.3\%). By far, the two most common locations where the burn injury occurred were the kitchen (43.3\%) and the bathroom (23.3\%), with the remaining 33.4\% of burn injuries occurring in a variety of places (e.g., bedroom, living room, basement, yard). Most children (30\%) were alone at the time of the burn injury; however, a number of children also were with their biological father (16.7\%), their biological mother (13.3\%), more than one adult (13.3\%), or a combination of adults and children (13.3\%). Remaining children either were with an older sibling aged 12-15 years (6.7\%), a grandparent (3.3\%), or an adoptive father (3.3\%) at the time of injury.

All children with burn injuries in this study had second, third, or a combination of second and third degree burns, with the percent TBSA of second degree burns ranging from $0-29 \%(M=$ 4.35, $S D=6.44)$ and the percent TBSA of third degree burns ranging from $0-13 \%(M=1.18, S D$ $=2.67)$. Percent TBSA of the entire burn ranged from $1-29 \%(M=5.50, S D=6.59)$. Approximately half of the children sustained burn injuries to more than one body part, with the other half sustaining burns to a single body part (e.g., hand, face). Children who were hospitalized for their burn injuries made up $46.7 \%$ of the sub-sample of youth with burn injuries. The remaining $53.3 \%$ of youth with burn injuries were treated through the outpatient burn care office. Across the 14 children who were hospitalized for their burns, the average length of hospitalization was 2.77 days $(S D=4.03)$. Of all children with burn injuries in this study, 76.7\% 
did not have a skin graft surgery, whereas $23.3 \%$ did receive a skin graft. With respect to family history of burn injuries, $16.7 \%$ of the children with burn injuries had a family history of burn injuries, whereas $83.3 \%$ did not. Of note, many of the burn characteristics (e.g., burn types, degree, TBSA, locations in the home of occurrence) of this sample are consistent with other samples of predominantly young children with burn injuries (e.g., Cronin et al., 1996; Rossi et al., 1998; Simon \& Baron, 1994).

Family demographic and household information. Descriptive statistics were calculated to describe family demographic information (e.g., family constellation) for case and comparison participants. Table 1 displays descriptive data of demographic variables that were balanced across groups during recruitment, whereas Table 2 illustrates descriptive information regarding demographic variables that the author did not balance during participant selection. Independent samples t-tests and Pearson chi-square analyses also were performed using group status as the independent variable and family demographic factors as dependent variables to compare the groups on balanced demographic variables (e.g., child age) and non-balanced demographic variables (e.g., number of children in the home). Whenever chi-square analyses resulted in too few cases (i.e., below the minimum number expected) in one or more cells, Fisher's Exact Test was used and is reported. No significant group differences were found for child age $[t(58)=.44$, $p=.66]$, gender $\left[\chi^{2}(1)=.27, p=.60\right]$, race $(p=1.00$, Fisher's exact test $)$, or geographic location $\left[\chi^{2}(1)=.09, p=.76\right]$, nor for caregiver marital status $\left[\chi^{2}(2)=1.03, p=.60\right]$ or SES as defined as the presence or absence of public financial assistance $\left[\chi^{2}(1)=1.31, p=.25\right]$. Likewise, there were no significant group differences in the number of adults in the home $[t(58)=0.00, p=$ 1.00], number of children in the home $[t(58)=1.62, p=.11]$, age of the primary caregiver $[t$ $(58)=.38, p=.71]$, work status of the primary caregiver $\left[\chi^{2}(2)=1.77, p=.41\right]$, education of the 
primary caregiver $\left[\chi^{2}(1)=.68, p=.41\right]$, family financial status according to an aggregate variable $[t(57)=.64, p=.53]$, frequency in which older siblings provide care for younger children $\left[\chi^{2}(1)=.84, p=.36\right]$, number of household smokers [ $\left.t(58)=1.23, p=.22\right]$, and number of caregiving hours per week by alternate caregivers in the home $[t(58)=.46, p=.65]$ and out of the home $[t(57)=.05, p=.96]$.

Caregiver psychological/behavioral functioning. The author also ran descriptive statistics on caregiver psychological and behavioral data by group for all participants in the present study (Table 3). Types of PAI scales on which participants scored in the clinically significant range are described by group in Table 4 . The clinicially significant scales displayed in Table 4 were endorsed by $25 \%$ of case participants and $26 \%$ of comparison participants who responded in a valid manner, with all other valid responders scoring within normal limits across all PAI scales. Overly positive responding on the PAI was evidenced among 6.7\% of case participants and $6.7 \%$ of comparison participants, with an additional 3.3\% of comparison participants responding inconsistently. On the PSI-SF, 30\% of case participants and 26.7\% of comparison participants responded in a defensive (i.e., overly positive) fashion. In terms of supervision, both case and comparison participants, on average, used protective supervision practices (i.e., close physical supervision and removal of the child from the hazard or vice versa) overall, across a number of hypothetical risk situations, with mean supervision levels ranging from mostly verbal directives to separation of the child from the hazard across participants in each group. Mean Overall Safety Knowledge Scores ranged from fair to good for both groups, with each group averaging somewhere between fair and good safety knowledge across a number of risk situations. With respect to observed safety measures, case and comparison participants on average practiced 
about half of all safety precautions examined, with mean Overall Safety Measures Scores ranging from mostly unsafe to mostly safe across participants in both groups.

Independent samples t-tests were performed to statistically compare the groups on psychological and behavioral variables of interest in the present investigation. There was no significant difference in the total number of clinically significant scales on the PAI for cases ( $M$ $=0.75, S D=1.88)$ and comparison participants $[M=0.63, S D=1.33 ; t(53)=.27, p=.79]$, nor was there a significant difference in total parenting stress scores for case $(M=70.33, S D=$ 16.30) and comparison participants $[M=65.91, S D=9.78 ; t(41)=1.09, p=.28]$. Likewise, there were no significant differences in the Overall Supervision Score on the PCSI for cases ( $M=$ 3.42, $S D=.53)$ and comparisons $[M=3.54, S D=.41 ; t(58)=-.94, p=.35]$ or the Overall Safety Measures Score on the OHSM for cases $(M=.48, S D=.19)$ and comparisons $[M=.51$, $S D=.18 ; t(58)=-.67, p=.50]$. A significant group difference was found, however, for the Overall Safety Knowledge Score on the HSKI. Case participants' overall knowledge scores ( $M=$ 2.46, $S D=.17$ ) were significantly less than those of comparison participants [ $M=2.56, S D=$ $.17 ; t(58)=-2.12, p<.05]$. The mean item scores on the HSKI for each group reveal that case participants, on average, scored lower than comparison participants across most items. Although not examined statistically, these differences suggest a pattern of less information across areas (e.g., burn and non-burn safety measures) among case versus comparison participants. Interestingly, both groups, especially the case group, scored relatively low on items pertaining to how to control the hot water temperature of the home (case $M=1.90, S D=.76$; comparison $M=$ 1.93, $S D=.69$ ), respond to a burn injury (case $M=1.87, S D=.73$; comparison $M=2.07, S D=$ .64), and respond to a smoke alarm sounding (case $M=1.93, S D=.25$; comparison $M=2.00$, $S D=.26)$. Comparison participants also scored relatively low on items regarding how to respond 
to a child's clothes catching on fire $(M=1.97, S D=.32)$ and detect smoke in the home $(M=$ 2.07, $S D=.25)$.

\section{Relation between Predictors and the Outcome of a Pediatric Burn}

Correlational analyses. The author performed a bivariate correlation analysis using the point-biserial coefficient $\left(r_{p b}\right)$ to examine the relation between the presence versus absence of a burn injury (i.e., outcome variable) and each (a) caregiver psychological/behavioral predictor (i.e., psychopathology, parenting stress, knowledge of home safety, supervision, and home hazard control) and (b) family demographic predictor (i.e., number of adults and children in the home; primary caregiver age, education, and work status; main other caregiver's work status; family financial status; frequency of older siblings providing care for young children; number of household smokers; and number of care-giving hours by non-primary caregivers in and out of the home). All participants were entered into this correlation analysis. Resulting correlations are displayed in Table 5 with statistically significant values indicated. The presence versus absence of a pediatric burn injury was not related to any demographic variables or the primary caregiver's mental health, parenting stress level, supervision style, or control of home hazards. There was a significant association, however, between the presence versus absence of a pediatric burn injury and the primary caregiver's home safety knowledge according to the Overall Safety Knowledge Score on the HSKI. Specifically, the greater the caregiver's home safety knowledge, the more likely the target child did not have a pediatric burn injury.

Discriminant function analyses. Due to the finding from correlational analyses that only one variable (i.e., the caregiver's overall safety knowledge on the HSKI) is significantly related to the outcome variable of the presence versus absence of a pediatric burn injury, no sequential discriminant function analysis was performed with family demographic predictors entered into 
the analysis first as cluster 1, parenting stress and caregiver psychopathology entered as cluster 2, and home safety knowledge and behaviors entered as cluster 3, in accord with previously stated hypotheses (Table 6). Although no set of predictors was found to significantly discriminate between groups in the present study, findings from correlational analyses suggest that the greater the primary caregiver's home safety knowledge, the more likely the caregiver can be classified as not having a young child with a burn injury.

\section{Relation between Predictors and Home Safety Behaviors}

Correlational analyses. The author performed a bivariate correlation analysis using the Pearson product-moment correlation coefficient $(r)$ to examine the relation between home safety behavior according to the PCSI (i.e., supervision; outcome variable) and (a) caregiver psychological/behavioral predictors (e.g., psychopathology) and (b) family demographic predictors (e.g., number of adults in the home). All participants were entered into this correlation analysis. Resulting correlations are displayed in Table 5 with statistically significant ones noted. No significant associations were found between the Overall Supervision Score on the PCSI and either caregiver psychopathology according to the PAI or parenting stress according to the PSISF; however, there was a significant relation between the Overall Supervision Score on the PCSI and the Overall Safety Knowledge Score on the HSKI. Specifically, a more protective or cautious supervision style by the primary caregiver across different situations with injury risk was associated with greater overall home safety knowledge by the caregiver. The only demographic variable that was significantly related to the Overall Supervision Score on the PCSI was the age of the target child; the younger the child, the greater or more protective the supervision practices of the primary caregiver. 
The author also performed another bivariate correlation analysis using the Pearson product-moment correlation coefficient $(r)$ to examine the relation between home safety behavior according to the OHSM (i.e., home hazard control; outcome variable) and each caregiver psychological/behavioral predictor and family demographic predictor. All participants were entered into this correlation analysis. Resulting correlations are shown in Table 5 with significant values tagged. A significant association was found between the Overall Safety Measures Score on the OHSM and total parenting stress according to the PSI-SF. The higher the parenting stress, the less environmental safety measures taken by the primary caregiver. No other significant relations were found between the Overall Safety Measures Score and other caregiver psychological/behavioral variables. The Overall Safety Measures Score on the OHSM was positively related to several demographic variables including the age of the primary caregiver, the primary caregiver's education (higher values indicate greater education), and the other main caregiver's work status (higher values indicate more time working). The Overall Safety Measures Score on the OHSM was negatively related to the following demographic variables: the age of the target child, an aggregate variable of family financial status (higher values indicate lower financial status), and the number of household smokers.

Hierarchical regression analyses. Caregiver psychological/behavioral and family demographic predictor variables that were significant in correlational analyses were considered for entry into hierarchical regression analyses as independent variables with the dependent variable being caregiver safety behavior. Because caregiver safety behavior scores according to self-report (i.e., PCSI) and observation (i.e., OHSM) were not highly correlated $(r=.05, N=60$, $p=.72$ ), two hierarchical regression analyses were performed, one using self-reported safety behavior with respect to supervision as the outcome measure and one using observed safety 
behavior with respect to home hazard control as the outcome variable. The general order in which predictor variables were entered into the hierarchical regression analyses is displayed in Table 6, consistent with study hypotheses. Of note, a power analysis for these hierarchical regression analyses revealed that the proposed number of participants is sufficient to detect a moderate effect size, which has been found in a similar hierarchical regression analysis in the general injury literature (Matheny, 1988).

The first hierarchical regression analysis consisted of the Overall Supervision Score on the PCSI as the dependent variable and the following significant predictor variables from correlational analyses: the age in months of the target child (cluster 1) and the Overall Safety Knowledge Score on the HSKI (cluster 2). The Overall Safety Knowledge Score was entered in cluster 2 as opposed to cluster 3 as displayed in Table 6 due to no significant relations between the Overall Supervision Score and caregiver parenting stress or psychopathology (i.e., hypothesized cluster 2 variables) in correlational analyses. This sequential regression analysis was performed to investigate whether or not the caregiver's overall home safety knowledge improved the prediction of the caregiver's supervision practices beyond that afforded by the age of the target child. Table 7 displays $R^{2}, R^{2}$ change, and $F$ values after entry of each predictor, as well as the unstandardized $(B)$ and standardized $(\beta)$ regression coefficients for each predictor in the final model (i.e., after entry of all predictors). The $R^{2}$ change was statistically significant at each step, with the age of the target child accounting for $28.4 \%$ of the variance in the caregiver's overall supervision practices, and the caregiver's home safety knowledge accounting for an additional $5 \%$ of the variance in the caregiver's supervision. Each variable was found to make a unique, statistically significant contribution to the prediction of caregiver supervisory behavior. 
The overall model with both independent variables in the equation was significant, $F(2,57)=$ $14.28, p<.001$

A second hierarchical regression analysis was performed with the Overall Safety Measures Score on the OHSM as the dependent variable. Due to 7 predictor variables (6 demographic and 1 psychological) proving to be significantly related to the Overall Safety Measures Score in correlational analyses and a sample size of 60, the author chose to enter the four predictors (i.e., 1 predictor for every 15 participants) that were most highly correlated with the Overall Safety Measures Score as independent variables in this hierarchical regression. These predictor variables were an aggregate family financial status variable (cluster 1), the number of household smokers (cluster 1), the work status of the main other caregiver of the target child (cluster 1), and the total parenting stress score according to the PSI-SF (cluster 2). This sequential regression analysis was performed to examine whether or not the caregiver’s parenting stress levels significantly increase the prediction of the caregiver's home hazard control beyond that afforded by related family demographic variables (e.g., family financial status). Table 8 displays $R^{2}, R^{2}$ change, and $F$ values at each step, as well as the unstandardized $(B)$ and standardized $(\beta)$ regression coefficients for each variable in the final model. The $R^{2}$ change was not statistically significant at either step 1 or 2 , though it approximated significance $(p=.06)$ at each step. Together, the family demographic/household variables entered in cluster 1 accounted for $22 \%$ of the variance in the caregiver's overall home safety measures, and the caregiver's parenting stress level accounted for an additional $9.2 \%$ of the variance in this outcome. None of the predictor variables were found to make a statistically significant unique contribution to the prediction of observed home safety; however, parenting stress, which made 
the greatest unique contribution, approached significance $(p=.06)$. The overall model with all independent variables in the equation was significant, $F(4,28)=3.17, p<.05$. 


\section{Discussion}

\section{Summary of Study Intent}

The main objective of this study was to investigate the contribution of caregiver psychological/behavioral variables to the prediction of (a) a burn injury in a young child and (b) caregiver safety behaviors (i.e., supervision and home hazard control), each after accounting for the prediction afforded by family demographic factors. The sample consisted of primary caregivers of young children with a burn injury (case group) and a demographically-balanced comparison group of primary caregivers of young children without a burn. The caregiver psychological/behavioral predictors of interest included psychopathology, parenting stress, home safety knowledge, supervision, and home hazard control, the latter two variables only for the outcome of a burn injury. Through this investigation, the author aimed to identify caregiver factors that may have an influential role in early childhood burn injuries and safety behavior, encourage future research in this area, and ultimately guide prevention initiatives.

\section{Summary of Main Findings}

The main findings of the present study were as follows: (a) comparison participants had significantly greater home safety knowledge than case participants, with no other psychological/behavioral variable significantly different between groups; (b) caregiver home safety knowledge was significantly related to the presence versus absence of a pediatric burn injury, with greater knowledge associated with less chance of a burn; (c) caregiver safety knowledge and the age of the target child were significant predictors of caregiver supervision in hierarchical regression analyses, with knowledge significantly improving the prediction of supervision beyond that afforded by age; and (d) parenting stress, in addition to several 
demographic predictors previously entered into the equation, accounted for a significant proportion of the variance in observed home hazard control.

\section{Group Differences in Caregiver Psychological and Behavioral Functioning}

Home safety knowledge. Comparison participants were found to have significantly greater overall home safety knowledge than case participants, as hypothesized, with both groups averaging somewhere between fair to good safety knowledge across a number of risk situations. In general, comparison participants appeared to have greater safety information across most areas than case participants, though mean differences in HSKI item scores were not examined statistically. Caregiver knowledge of general home safety including burn safety may translate into greater supervision and/or greater home hazard control over time and in turn, provide some protection against the occurrence of a child burn injury. The finding of greater home safety knowledge among comparison participants compared to case participants is in line with previous burn research that found a lack of specific home safety information among guardians of children with burn injuries (Cronin et al., 1996; Rossi et al., 1998), though no overall knowledge scores were generated in this previous research for comparison to those in the present study. These studies also did not examine home safety knowledge in a comparison group; thus, the authors could not conclude that the knowledge deficits that were found exceeded those of guardians of children without burns. The present study found insufficient safety knowledge in certain areas (e.g., burn first aid) among both case and comparison participants, which is consistent with previous research that has identified inadequate burn first aid information, for instance, among caregivers of children both with burn injuries (e.g., Cronin et al.) and without (Liller et al., 2001). Overall, however, and distinct from prior research, findings from the present study 
suggest significantly greater home safety knowledge among caregivers of young children without burns than among those of children with burns.

Psychopathology. Contrary to expectations, no significant group difference in caregiver psychopathology emerged. This finding is inconsistent with those of general injury researchers (e.g., Matheny, 1988); however, general injury and burn research in this area is quite limited. Interestingly, in the current study, the percentage of participants with at least one clinically significant scale score on the PAI (i.e., 25\% of case participants and 26\% of comparison participants) and at least one clinically significant score on a clinical scale (i.e., $18 \%$ of cases and $22 \%$ of comparisons) is not insignificant. Perhaps the similar rates of mental health issues among case and comparison participants may be explained in part by certain demographic factors (e.g., poverty) that were represented comparably across groups and have been associated with psychopathology (Costello, Compton, Keeler, \& Angola, 2003). All of the four participants (two case and two comparison) with four or more clinically significant scale scores had low income, for example, and in most cases, low financial status by multiple markers. In groups that are similar across many demographic factors (e.g., financial status, education, marital status), differences in psychopathology may be reduced. It also is possible that there was not enough power to detect a group difference in caregiver psychopathology due to a small sample size. Another possibility is that increasing psychopathology does not put young children at greater risk of a burn in a linear fashion. Rather, it could be that only an extreme amount of psychopathology places children at risk. Findings from the present study are in line with this possibility. Specifically, one case participant had eight clinically significant scale scores and another had six, whereas no comparison participants had greater than five clinically significant scores. 
The role of extensive psychopathology could be examined in future research with samples sufficiently large to capture enough extensive psychopathology. Future research also might benefit from exploring statistical differences in certain types of psychopathology using larger samples given that some mental health problems (e.g., borderline and antisocial personality features) were evidenced more among the case group than the comparison group in the present study. Another important question for future research is whether or not untreated versus treated psychopathology makes a difference in terms of child burn injury risk. The fact that two case participants and no comparison participants had clinically significant scores on the treatment rejection scale, which assesses the degree to which one is likely to reject personal change and treatment, lends support to exploring this question.

Parenting stress. Mean total parenting stress scores on the PSI-SF were within normal limits for both groups, with no significant between-group differences, contrary to expectations. These findings should be interpreted with caution, however, because $30 \%$ of case participants and $26.7 \%$ of comparison participants responded defensively on the PSI-SF and therefore were not included in the analyses. Consequently, parenting stress findings may not be representative and possibly reflect an underestimation of true parenting stress experienced among this sample. Given similar amounts of defensiveness across groups, however, there is no reason to think that a group difference in parenting stress would have emerged had all participants responded in a valid manner. The absence of a group difference in parenting stress is most similar to the results of Blakeney et al. (1993) from the burn literature. As was stated with respect to their findings, it is possible that the burn injury minimizes parental perception of pre-burn parenting stress or that caregiver stress non-specific to parenting is more strongly associated with child burn injuries. 
The latter possibility is consistent with the findings of Vaughan et al. (2004), which suggest that maternal stressful life events may increase child injury risk.

Supervision. One possible explanation for the lack of a between group difference in caregiver supervision as measured by the PCSI is that responses on the PCSI were influenced by social desirability, perhaps more so for the case group than the comparison group given that the former group, having had a child sustain a burn injury, may have felt more sensitive about their supervision practices than the latter. The PCSI does not have validity scales to check for overly positive responding, and although it has an open-ended response format, the responsible or safe thing to do is not obscure for some items. For example, most caregivers probably know that leaving a young child alone in a car (item 6) or outside in an unfenced yard (item 4), even for just a moment, is not considered safe; however, that does not mean that they do not do it at times. The high mean scores for each group also lend support to the possibility of a social desirability influence. Another reason for treating these findings with caution is that the Overall Supervision Score on the PCSI had unsatisfactory internal consistency, similar to that reported for the MSI (Dal Santo et al., 2004; Greaves et al., 2004) on which it is based. Furthermore, the Overall Supervision Score is derived from 7 of the 18 original items due to item deletions largely to improve the internal reliability of the measure. Thus, this summary score represents supervisory practices on a limited sample of child hazard scenarios. It is difficult to compare the present supervision findings to those in the burn literature because the burn literature generally has examined supervision at the time of the burn injury rather than in general across everyday situations. The finding that participants, on average, used highly protective supervision (i.e., close physical supervision and removal of the child from the hazard or vice versa) across various risk situations in the present study is not dissimilar from the results of Garling and Garling 
(1995), which suggest that the most common supervision practice used by parents of young children to try to prevent a child injury is restricting the child from the hazard or changing the environment (e.g., moving the hazard away from the child). The lack of a significant group difference in supervision, however, is contrary to those findings of Garling and Garling that suggest that maternal supervision affords children some protection against injury. Unlike the present study, however, supervision and the child’s injuries were reported by mothers in Garling and Garling’s study. Same method variance could account in part for their findings.

One idea for future research would be to try to improve the internal reliability of the MSI or the PCSI, maybe by reducing face valid items and identifying, through pilot studies or focus groups, common risk situations that solicit a greater variety of supervision approaches (i.e., a good range of responding) across caregivers of young children. Perhaps greater scoring guidelines, based on well-established, consensus-derived standards for appropriate supervision, which currently are lacking (Damashek \& Peterson, 2002), also would improve the internal consistency of the measure. Although the two coders of supervision responses in the present study demonstrated satisfactory scoring reliability across groups, some responses were challenging to score based on the general scoring guidelines for the MSI and therefore required additional guidelines, which the author created to the best of her ability based on knowledge of child development, child injury prevention, and judgment. Standards of appropriate supervision for young children of various ages in specific risk situations (e.g., being at a playground with older children who are playing roughly), however, may have reduced scoring inconsistencies across situations for a given participant. Currently, there is no well-established consensus regarding whether or not removing a 5-year old child from a playground with children who are playing roughly is better supervision practice than providing close physical supervision of the 
child on the playground at a distance from the older children, for example. It is recommended that future research prioritize the development of standard supervision recommendations for young children of different ages in various risk scenarios. Researchers also may want to consider developing an observational measure of supervision in an effort to improve the internal reliability and validity of scores. With funding assistance, burn researchers could provide caregivers with a video camera to tape bath time and meals with the target child over a discrete period of time (e.g., 3-7 days) and rate the frequency and/or duration of various supervision practices (e.g., verbal directives and physical supervision) used in brief time intervals.

Home hazard control. The lack of a significant group difference in the safety of the home also was unexpected. This finding partially may reflect participant reactivity to observation, perhaps greater among case participants than comparison participants given aforementioned sensitivity issues. That is, case participants, in particular, may have modified their homes (e.g., put batteries in the smoke detector) to make them appear safer to the observer, even though steps were taken to reduce participant anxiety about the home visit. It also is possible that case participants made their homes safer (e.g., pushed kitchen appliances to the back of the counter) following the burn incident to prevent a future injury. Although the author attempted to prevent the transfer of burn safety information to case participants when they were at the Burn Unit or the outpatient burn care office, participants may have gathered safety information from a burn care provider who was less familiar with the study (e.g., a fill-in nurse) or on their own (e.g., from relatives). Participants also may have made their homes safer (e.g., less cluttered) following the child's burn injury based on common sense. The absence of a significant group difference in home safety also could be explained by the OHSM, especially one-time use of it, lacking sensitivity to measure actual home hazard control. For example, the presence of a kitchen safety 
gate in the home does not mean that it is used consistently during cooking. Another possible explanation for the lack of a between group difference in overall home safety scores is that some items with relevance to early childhood burns and this sample in particular (e.g., accessibility of any plugged-in clothes or curling iron) often could not be observed (e.g., due to no iron being plugged in at the time of observation) resulting in a preponderance of missing data for those items and ultimate removal of those items from the analyses. Another important point is that the home visits occurred with primary caregivers even though they may not have been caring for the child at the time of injury. For those children who were not in the care of the primary caregiver at the time of injury, observational data may reflect a less hazardous environment than present at the time of injury.

Although less probable, other factors that may have influenced the finding of a nonsignificant group difference in home safety include possible observer error and bias in observational ratings. For example, an observer may have scored “accessibility of all cleaners” as "safe" when in actuality the observer did not see one cleaner that was within reach of a young child. It is possible that observers felt less comfortable looking as carefully in case participant homes than in comparison participant homes given greater perceived sensitivity among case participants. In this way, observer error might have been greater in case participant homes. On the other hand, observers were not blind to group status, and it is possible that bias negatively influenced ratings for case participants more so than comparison participants, even though objective guidelines were provided for all ratings. It bears mentioning, however, that observer reliability, obtained for $20 \%$ of the home visits and evenly distributed across group, was good. Consequently, potential observer error and bias in ratings probably was minimal. 
The non-significant group difference in home hazard control is inconsistent with previous burn research that found significantly greater home safety measures taken by caregivers of children without burns than those of children with burns (Petridou et al., 1998) and more flammable substances in the homes of children with versus without burns (Forjuoh et al., 1995). Discrepant findings may be explained by a number of differences between these studies and the present one such as the method (i.e., self-report of behavior over time versus one-day observation of behavior), the number of safety measures examined (i.e., few versus multiple), the type of safety measures examined, and the setting (i.e., Greece and Ghana versus the U.S.). The present findings also are contrary to previous general injury research that found that young children with injuries lived in more hazardous homes than those without injuries (e.g., Matheny, 1988). It is important to note, however, that the present findings are not necessarily inconsistent with the large body of literature demonstrating home safety problems in the homes of young children without injuries (e.g., Morrongiello \& Kiriakou, 2004). For example, the present finding that participants in both groups, on average, adhered to approximately $50 \%$ of evaluated home safety precautions is similar to the findings of Morrongiello and Kiriako, which suggest that mothers of young children average 56\% adherence to home safety measures across a number of home safety measures that were assessed. Although the safety precautions examined in the present study differ in part from those examined by Morrongiello and Kiriakou (and in other previous research), some of the safety measures that were not practiced by the majority of caregivers across groups in the present study (e.g., lowering the hot water temperature of the home) have been shown to have poor adherence rates by caregivers of children without injuries in previous research (e.g., Gielen et al., 1995; Morrongiello \& Kiriakou). Taken together, one 
cannot rule out the possibility that the present findings reflect a true lack of distinction between the home hazard control practices of caregivers of children with and without burn injuries.

Although time consuming and potentially costly, one suggestion for future research is to obtain more than one sample of home hazard control. Repeated observations might reduce participant reactivity based on habituation and provide a more representative picture of typical home safety practices over time. On the other hand, repeat observations could begin to function like an intervention in which the behavior observed is a response to an earlier observation(s). Another idea for future research is to conduct home observation during a hazardous time or situation (e.g., cooking, bathing, or getting ready in the morning) to better understand home safety when certain hazards are in use. Ratings could focus on the use of certain safety devices (e.g., safety gate during cooking) and placement of certain hazards (e.g., pot on the stove and curling iron) during these times. It also might be important for the caregiver who was present with or responsible for the child at the time of injury to be present during the observation to better understand hazard control by the caregiver in question.

\section{Relation between Predictors and the Outcome of a Pediatric Burn}

In light of the previous discussion, it is not surprising that caregiver home safety knowledge was the only caregiver psychological/behavioral factor significantly associated with group status in correlational analyses. After controlling for demographic factors in the selection

of the case and comparison group, no family demographic variables were significantly related to group status either. The greater the caregiver's safety knowledge, the more likely the caregiver did not have a child with a burn. To the author's knowledge, no other study in the general or burn injury literature has identified caregiver home safety knowledge as a significant predictor of an injury to a young child after controlling for child, caregiver, and family demographic factors 
through a case group and a demographically-balanced comparison group. As mentioned earlier, it is thought that the caregiver's home safety knowledge may decrease the likelihood of an early childhood burn injury by translating over time into more protective supervision and/or greater control of home hazards. Given that greater caregiver home safety knowledge was significantly associated with greater caregiver self-reported supervision but not greater home hazard control in the present study, greater home safety knowledge may have influenced better supervision more than observed home hazard control among this sample. Considering previously discussed caveats of the home observational data (e.g., one-time data collection), however, the possibility that greater home safety knowledge influenced greater home safety behavior should not be ruled out. Some of the aforementioned recommendations to improve observational data of home safety, such as repeat observations, might shed light on this possibility. Same method variance also partially could explain why caregiver safety knowledge was significantly related to supervision (same methods) and not home hazard control (different methods).

Given that neither caregiver self-reported supervision or observed hazard control, two types of safety behaviors, were significantly related to the outcome of a pediatric burn injury in the present study as expected based on previous research findings (e.g., Carrigan et al., 1988; Petridou et al., 1998) and the theoretical importance of these variables in child injury prevention (Wortel et al., 1994), another avenue for future research would be to evaluate the ability of these constructs taken together (e.g., protective supervision in hazardous environments, poor supervision in minimally hazardous environments) to predict an early childhood burn. Perhaps it is the combination of some unknown deficit in supervision and some unknown deficit in home safety that puts children at significant risk of a burn injury. Looking at these constructs in isolation may not be as productive as looking at these constructs together. An observational tool 
used repeatedly during situations with varying apparent hazard levels, in particular, might best capture actual caregiver supervision practices across time and context.

\section{Relation between Predictors and Supervision}

One interesting finding in the prediction of caregiver supervison was that the child's age was the single most important predictor, with the two variables inversely related. The inverse association between child age and the level of protectiveness of the caregiver's supervision has been found in previous studies with young children (e.g., Garling \& Garling, 1995). Moreover, the finding repeatedly has troubled researchers given that toddlers, due to greater mobility, are at increased risk of certain injuries than infants, and preschool children generally are not able to calculate and manage risks in their environment (Wortel et al., 1994), even with verbal guidance, as many parents think (Garling \& Garling). Interestingly, this study showed that caregiver knowledge significantly adds to the prediction of supervision after accounting for the prediction afforded by the child’s age. Specifically, greater caregiver home safety knowledge influences more cautious supervision. Perhaps caregivers with greater safety knowledge better understand the importance of cautious supervision methods for all young children than do caregivers with less safety knowledge. While this finding has positive implications for prevention, as later discussed, it is important to note that the child's age accounts for a much greater proportion of the variance in supervision than does the caregiver's knowledge after accounting for the child's age. In fact, the amount of variance in supervision accounted for by the child's age is rather humbling and highlights the importance of education about child development and injury risk for preschool aged children.

Furthermore, 67\% of the variance in supervision remains unaccounted for by any variable examined in this study. The lack of prediction from other demographic variables, parenting 
stress, or caregiver psychopathology is counter to expectations and somewhat puzzling but may be explained by the aforementioned limitations with some study measures, the PCSI in particular (as it is the common variable across these findings). For example, the unsatisfactory internal consistency of the PCSI suggests that these findings should be interpreted with caution. Furthermore, the restricted range of supervision scores in the present sample, perhaps due to the influence of social desirability, might have limited power to detect significant correlations. Another possible explanation for these findings given that parents generally are intrinsically motivated to promote their offspring's chance of survival (Sluckin \& Herbert, 1986) is that some level of caregiver supervision of children is biologically ingrained and reflexive, and therefore less affected by potential stressors, such as single parenthood, low income, parenting stress, and mental health difficulties. In other words, the drive to protect one's offspring through some supervisory effort, however inadequate, may be somewhat fixed regardless of demographic or psychological circumstances. The present regression findings suggest, however, that the type of supervision (e.g., verbal instruction versus physical supervision) does vary based largely on beliefs about the needs of children at various ages and information about home safety.

It would be interesting to see the results of this analysis using a more internally consistent and less face valid measure of caregiver supervision, such as ones suggested previously. Another idea for future research would be to evaluate the effects of education about child development and injury risk for preschool aged children on caregiver supervision of children aged 0-5 years. Future research also might benefit from examining other variables that could account for caregiver supervision practices such as the caregiver's perception of risk involved in various situations (e.g., cooking with help from a 4-year old child). 


\section{Relation between Predictors and Home Hazard Control}

In correlational analyses, home hazard control was significantly associated with a number of demographic factors as well as parenting stress. The inverse relation between caregiver home hazard control and child age is consistent with that between caregiver supervision and child age. It appears that caregivers perceive less need for home hazard control as well as supervision as children move from infancy to the toddler and preschool years, even though preschool children are more physically able to come in contact with some hazards than infants. Direct relations between home safety and caregiver age, education, and financial status were as predicted based on research findings demonstrating a negative relation between child injury and caregiver age (e.g., Brenner et al., 1999) and between child burn injuries and caregiver education (e.g., Forjuoh et al., 1995) and financial status (e.g., Slater et al., 1987). The positive relation between hazard control and time spent working by a secondary caregiver may be explained by less work demands on the primary caregiver, thereby enabling the primary caregiver more time for home safety. The negative association between home hazard control and the number of household members who smoke may be explained by a lack of awareness of or attention to child health needs, greater stress among families with multiple smokers, or difficulty controlling hazards (e.g., matches) when smoking. Finally, the inverse relation between home safety and parenting stress was as expected, in part based on the finding that maternal stress increases child injury risk after controlling for other factors (Vaughan et al., 2004).

What is most remarkable about the findings of hierarchical regression analyses with home hazard control as the outcome variable is that a significant amount of variance in this outcome is not accounted for until parenting stress is added to the equation. Furthermore, parenting stress is the single largest predictor of home safety. Caregivers who feel stressed in the 
parenting role may have or perceive fewer resources (time and mental) for home safety. Furthermore, caregivers with high parenting stress may not take home safety precautions due to (a) poor self-efficacy as a parent to influence positive child outcomes; (b) perception of a difficult child who is unlikely to respect the caregiver's safety measures (e.g., kitchen safety gate); and/or (c) negative parent-child interactions that create distance, resentment, or hostility between the caregiver and child. Although parenting stress could influence poor home hazard control as described above, it is important to note that hazardous environments also could influence greater parenting stress. The direction of influence between parenting stress and observed home safety cannot be ascertained by the present study. Interestingly, although parenting stress is the only pure psychological predictor of observed home hazard control in the present study, each of the demographic predictors entered into this regression analysis carry a potential stress factor that could be at work. Parental stress is recognized as an important factor for consideration in child injury prevention (e.g., Libber \& Stayton, 1984), and maternal stressful life events have been related directly to child injuries among a low-income sample (Vaughan et al., 2004). Perhaps a global stress factor that incorporates different types of stress (e.g., major life events, daily hassles, parenting, marital, health-related) would be a strong predictor of home hazard control. Examination of a global parental stress factor is advised for future research.

It bears mentioning that $69 \%$ of the variance in home hazard control remains unaccounted for by factors investigated in this study. The lack of prediction accounted for by other demographic variables (e.g., marital status), psychopathology, and particularly home safety knowledge is contrary to hypotheses. The non-significant relations between these variables and home hazard control may be explained in part by previously described limitations of the dependent measure. The restricted range of scores for this measure (i.e., "0" to " 1 ”) also might 
have limited power in correlational analyses. Possibly, certain demographic factors (e.g., caregiver marital status and number of children in the home) may not be as relevant to caregiver home hazard control in the present sample compared to some samples due to many participants having extended family and non-family caregivers for their children. As previously discussed, caregiver psychopathology may not be related to home safety in a linear fashion; instead, it could be that only extreme amounts of psychopathology, certain types of psychopathology, or untreated psychopathology influences home hazard control. The lack of a significant relation between home safety knowledge and home hazard control could be explained by method variance. It also is possible that caregiver home safety knowledge does not influence home hazard control as it seemed to influence supervision. Research has shown that safety knowledge does not necessarily translate into safety behavior as described in Damashek and Peterson (2002). In this study with only one home observation, however, what may to be more likely is that home safety knowledge does not always influence hazard control but may influence it at times (e.g., during bathing) and over time. Future research might consider what other variables could account for home hazard control, such as the caregiver's perception of the cost and benefit of various safety devices and other hazard control efforts (e.g., keeping matches in a locked place).

\section{Strengths and Limitations}

Knowledge from prior research was instrumental in shaping the current investigation, and the author strove to build upon the work of others. Strengths of this study include (a) focus on one type of injury and a specific age group of children at particular risk of this injury; (b) a well-balanced comparison group; (c) recruitment of case participants from medical facilities with injury data; (d) recruitment of comparison participants from multiple sites with different 
demographics; (e) within-group diversity across the majority of demographic variables; (f) diversity in early childhood burn injury characteristics (e.g., type and inpatient versus outpatient treatment); (g) inclusion of non-mother primary caregivers, though limited in number; (h) examination of variables amenable to treatment; (i) multiple assessment methods; (j) efforts to maximize the validity of self-report measures (e.g., standardized tools with validity scales and interviews with open-ended response formats); (k) multiple informants when possible; (l) homebased data collection of safety variables (i.e., knowledge, supervision, and hazard control); (m) good overall observer and coder reliability on a subset of the sample throughout the study; and (n) adjustment for confounding variables in hierarchical regression analyses.

Study limitations to address in future research include (a) recruitment from one geographic region; (b) greater refusal to participate in the case group than the comparison group, thereby calling into question the representativeness of the case group particularly; (c) a relatively small sample, thereby restricting generalizability and power; (d) a predominantly Caucasian sample; (e) limited representation of non-mother primary caregivers and examination of alternate caregivers; (f) one-time data collection for all variables; (g) data collection after the time of injury for the case group, thereby raising the possibility of an injury influence in findings; (h) a significant proportion of invalid responding on the PSI-SF; (i) a potential social desirability influence on the PCSI; (j) unsatisfactory internal consistency and reduced content validity of the PCSI and HSKI following item deletions; (k) potential participant reactivity to home observation; (l) difficulty observing some home safety measures, thereby reducing the content validity of the OHSM; (m) possible lack of sensitivity to measure constructs of interest with certain newly developed or modified measures; and (n) inability to draw conclusions regarding causality by nature of the design. In addition to using prospective, longitudinal designs, it is 
recommended that researchers perform functional analyses of early childhood burn injuries and risk behavior, as has been suggested for child injuries in general (Saldana \& Peterson, 1998; Wortel et al., 1994) to help ascertain factors that may contribute to and maintain these problems. Additional Directions for Future Research

Outside of caregiver factors investigated in the present study and mentioned earlier for future study, there are other caregiver factors that deserve attention in relation to early childhood burn injuries and caregiver safety behaviors. For example, based on the findings of Harel (1988) from the general injury literature, it would be worth examining the contribution of caregiver physical health to early childhood burn injuries and safety practices. Additionally, considering that almost $75 \%$ of parents (fathers more than mothers) of young children in a recent study by Lewis, DiLillo, and Peterson (2004) stated believing to some extent that minor injuries have developmental benefits to children, such as toughening them and teaching them to be more careful, future research should examine the contribution of caregiver beliefs regarding injury to the outcomes of early childhood burns and safety behavior. Given the findings of Schwebel et al. (2004), which revealed that positive parenting (e.g., structured child activities) was significantly associated with less child injuries, parenting skill variables (e.g., structured child activities and limit setting) may be important in child burn injury outcomes as well. It is thought that studying the contribution of these caregiver factors relative to the ones that were significant in this study, after controlling for relevant demographic factors, would be especially informative.

Although this study focused on caregiver predictors of early childhood burns and caregiver safety behaviors, it is important for future research to examine the relative importance of caregiver predictors, child predictors, and caregiver-child interaction predictors (e.g., child responsiveness to caregiver rules) in these outcomes. Prior research has supported a significant 
relation between child injury and child factors (e.g., child behavioral problems; Schwebel, Speltz, Jones, \& Bardina, 2002), as well as between child injury and parental factors (e.g., poor supervision; Carrigan et al., 1988); however, research, particularly specific to burn injuries, is lacking when it comes to the relative role of child versus caregiver factors. Some researchers (e.g., Vaughan et al., 2004) recently have raised the possibility that parent-child interaction factors (e.g., the goodness of fit between parenting and child behavior) may contribute further to the prediction of child injuries, above that afforded by child and parental factors independently. This question is an empirical one that also warrants attention in future research.

\section{Implications for Prevention}

The present study suggests that certain caregiver psychological/ behavioral factors significantly improve the prediction of a burn injury in a young child and caregiver safety behaviors beyond that afforded by family demographic variables alone. One main implication of these findings is that attention to certain caregiver psychological and behavioral factors may help professionals identify which young children are at increased risk of a burn injury. Another important implication is that some risk factors for early childhood burn injuries may be amenable to intervention and therefore, a young child's risk of a burn injury may be reduced.

Professionals working with young children should be attuned to caregiver home safety knowledge and parenting stress, the latter especially in conjunction with certain demographic risk factors, given that these caregiver factors in particular may place young children at increased risk of a burn. Pediatricians, who routinely see young children and their caregivers and provide basic home safety information in conjunction with developmental milestones as part of standard care, should regularly assess the caregiver's acquisition of previously reviewed home safety information. Pediatricians also should take note of caregivers who appear or describe themselves 
as highly stressed in the parenting role. Mental health professionals who work with young children inevitably will work with their caregivers and should take note of basic home safety knowledge gaps that may become apparent. For example, if a caregiver describes a child tantrum in the kitchen when the caregiver was cooking, the mental health professional should recognize the need for home safety information at least in regard to keeping young children out of the kitchen during meal preparation. Mental health professionals also should monitor parenting stress. The PSI-SF could be administered by qualified mental health professionals who suspect high parenting stress to determine whether or not it falls within a clinically significant range. Other professionals who may be in good positions to monitor caregiver safety knowledge and parenting stress include daycare providers and preschool and kindergarten teachers who likely have training in child safety in addition to frequent contact with young children and their caregivers. Any child who presents to a medical facility with a burn injury should not be sent home before the safety knowledge and parenting stress of the primary caregiver have been evaluated and addressed. Especially in these serious situations, the HSKI and PSI-SF might be useful assessment tools. Children with burn injuries are at increased risk of another burn by their history of a burn alone. Close attention to the caregiver's home safety knowledge and parenting stress, however, may identify factors that could be addressed and in turn, possibly reduce the risk of a future burn.

Caregivers who demonstrate a lack of basic home safety knowledge might benefit from home safety brochures or handouts, which child injury prevention professionals could disseminate to primary care, daycare centers, preschools, and emergency and urgent care. Other caregivers may benefit more from discussion of home safety information with the opportunity to ask questions. Pediatricians who can afford to spend time talking about home safety with 
caregivers are an excellent resource for doing so due to their regular contact with young children and the amount of trust that caregivers tend to place in them. Daycare providers and teachers of young children also might be able to discuss important home safety precautions with caregivers who are lacking information. Given the time constraints that often are placed on these professionals, however, an alternate suggestion is to refer these caregivers to a pediatric psychologist with an injury prevention focus or a home safety education program, often sponsored through medical facilities and community public health agencies. Caregivers who are recognized as lacking home safety information at a medical facility following a pediatric burn injury should be able to meet with a qualified professional (e.g., pediatric psychologist or child life specialist) who could provide home safety information on site. Some caregivers, however, may be too upset at the time of injury to retain such information. In these situations, information could be provided prior to discharge (if the child is hospitalized), at an outpatient appointment, or during a scheduled home visit. Home visits are an ideal site for providing home safety information in that the home is usually non-threatening for caregivers, and home safety information can be tailored to the individual home. Corrarino, Walsh, and Nadel (2001) found that delivery of scald prevention information by public health nurses in the home resulted in significant changes in scald prevention practices by parents. They attributed these changes in part to social support provided by the nurses in the home. Through their review of home safety education programs for caregivers, Damashek and Peterson (2002) suggest that education in the home may be more effective than less tailored educational methods.

Broadly speaking, home safety information for caregivers should include coverage of risks and hazards for young children, home hazard control including safe placement of hazards and the use of safety devices, how to apply safety devices, the importance of supervision, and 
basic first aid (Glik, Kronenfeld, \& Jackson, 1993). Given that caregivers seem to overestimate the risk management abilities of preschool children (Garling \& Garling, 1995), information on child development and injury risk for all young children also is important. Findings from the present study suggest that caregivers may have the least safety knowledge with respect to controlling the hot water temperature of the home, applying burn first aid, detecting smoke in the home, and responding to either a smoke alarm going off or a child's clothes catching on fire. These areas may be important to highlight in home safety education efforts. Additional suggestions include providing verbal and written information in lay language, incorporating visual aids into written materials to promote learning, and making written materials visually appealing to increase their user draw. It also might be helpful for home safety information to include information on where certain safety devices can be purchased, ideally for not too much cost. In their review on the topic, Damashek and Peterson (2002) report that education programs that include free safety devices may be more effective that those that offer education alone, though both types of programs have demonstrated effectiveness and more research is needed. Wortel et al. (1994) suggest that educators take into account the caregiver's thought processes with respect to injuries (e.g., their risk and cost) and help caregivers understand both threats to the child's safety as well as the reduction in child injury risk when precautions are taken.

Caregivers who exhibit or report high parenting stress most likely would benefit from referral to a child clinical psychologist or other mental health counselor with training in child behavior and parenting. If the caregiver also experiences stress outside of parenting, perhaps in relation to financial strains, he or she may benefit additionally from seeing an adult-oriented counselor for stress management and other therapy needs, as relevant. In other words, although 
certain demographic risk factors (e.g., poverty) may be difficult to change, therapy may be able to help one cope with associated stress, thereby reducing the negative impact of these factors.

Professional attention and response to home safety knowledge and parenting stress may influence reduced child burn risk. Furthermore, this targeted approach may be cost effective in that it focuses resources on children who may be at increased risk. Nonetheless, in the case of home safety knowledge, the sole predictor of an actual pediatric burn in the present study, one more proactive and controlled approach would be to provide it routinely as part of pre-natal care, before a parent becomes a parent. An expecting parent for the first time might be more likely to invest in home safety devices before a baby is born than after a baby and his or her many needs arrive. One limitation of this approach, however, is that it would not reach individuals who do not receive pre-natal care. Efforts to reach these individuals through other means (e.g., free-care clinics) would be important. Another limitation is that some expecting parents for the first time may be less able to appreciate and absorb home safety information prior to having children compared to after when the needs for it may be more apparent. A first-time expecting parent also may be too preoccupied with other things (e.g., the delivery) to process home safety information. Alternatively, home safety information could be provided universally through well-child care visits, in greater depth than currently is provided through this medium, with content matching the child's developmental level, as is the general approach among pediatricians. Although pre-natal care visits typically are carried out by obstetricians and midwives, and well-child care visits typically are conducted by pediatricians, an injury prevention professional (e.g., pediatric psychologist or public health nurse) could be integrated into either as part of standard care. A professional with this specialty and purpose might be in a better position to provide home safety information effectively (as described above) than a medical professional with different training 
and other responsibilities at a pre-natal or well-child care visit. Such a professional also might be able to further discuss home safety in the home, as necessary. Whether through pre-natal or wellchild care, standardizing the provision of home safety information might have far-reaching benefits with respect to child burn injury prevention and, in the long run, be more cost effective than a targeted approach through which many caregivers and young children could slip through the cracks. 


\section{References}

Abidin, R. R. (1995). Parenting Stress Index professional manual (3rd ed.). Odessa, FL: Psychological Assessment Resources, Inc.

Barret, J. P., Desai, M. H., \& Herndon, D. N. (2000). The isolated burned palm in children: Epidemiology and long-term sequelae. Plastic and Reconstructive Surgery, 105, 949-952.

Blakeney, P. (1994). School reintegration. In K. J. Tarnowski (Ed.), Behavioral aspects of pediatric burns (pp. 217-241). New York, NY: Plenum Press.

Blakeney, P., Moore, P., Broemeling, L., Hunt, R., Herndon, D. N., \& Robson, M. (1993). Parental stress as a cause and effect of pediatric burn injury. Journal of Burn Care and Rehabilitation, 14, 73-79.

Bobak, M., Pikhart, H., \& Koupilova, I. (2000). Maternal socioeconomic characteristics and infant mortality from injuries in the Czech Republic 1989-92. Injury Prevention, 6, 195-198.

Brenner, R. A., Overpeck, M. A., Trumble, A. C., DerSimonian, R., \& Berendes, H. (1999). Deaths attributable to injuries in infants in the United States: 1983-1991. Pediatrics, 103, 968-974.

Carrigan, L., Heimbach, D. M., \& Marvin, J. A. (1988). Risk management in children with burn injuries. Journal of Burn Care and Rehabilitation, 9, 75-78.

Cassell, O. C. S., Hubble, M., Milling, M. A. P., \& Dickson, W. A. (1997). Baby walkers - still a major cause of infant burns. Burns, 23, 451-453.

Chedekel, D. S., Rizzone, L. P., \& Antoon, A. Y. (1998). Burns. In R. T. Ammerman \& J. V. Campo (Eds.), Handbook of pediatric psychology and psychiatry (Vol. 2, pp. 191-205). Boston, MA: Allyn and Bacon. 
Christophersen, E. R., \& Purvis, P. C. (1991). Injury control in children. In M. Hersen \& R. M. Eisler (Eds.), Progress in behavior modification (Vol. 27, pp. 104-121). Newbury Park, CA: Sage Publications, Inc.

Corrarino, J. E., Walsh, P. J., \& Nadel, E. (2001). Does teaching scald burn prevention to families of young children make a difference? A pilot study. Journal of Pediatric Nursing, 16, 256-262.

Costello, J. E., Compton, S. N., Keeler, G., \& Angold, A. (2003). Relationships between poverty and psychopathology: A natural experiment. Journal of the American Medical Association, 290, 2023-2029.

Crawley, T. (1996). Childhood injury: Significance and prevention strategies. Journal of Pediatric Nursing, 11, 225-232.

Cronin, K. J., Butler, P. E. M., McHugh, M., \& Edwards, G. (1996). A 1-year prospective study of burns in an Irish paediatric burns unit. Burns, 22, 221-224.

Dal Santo, J. A., Goodman, R. M., Glik, D., \& Jackson, K. (2004). Childhood unintentional injuries: Factors predicting injury risk among preschoolers. Journal of Pediatric Psychology, 29, 273-283.

Damashek, A., \& Peterson, L. (2002). Unintentional injury prevention efforts for young children: Levels, methods, types, and targets. Journal of Developmental and Behavioral Pediatrics, 23, 443-455.

Division of Injury Control, Center for Environmental Health and Injury Control, \& Centers for Disease Control (1990). Childhood injuries in the United States. American Journal of Diseases in Childhood, 144, 627-646. 
Eichelberger, M. R., Gotschall, C. S., Feely, H. B., Harstad, P., \& Bowman, L. M. (1990). Parental attitudes and knowledge of child safety. American Journal of Diseases of Childhood, 144, 714-720.

El-Badawy, A., \& Mabrouk, A. R. (1998). Epidemiology of childhood burns in the burn unit of Ain Shams University in Cairo, Egypt. Burns, 24, 728-732.

Faelker, T., Pickett, W., \& Brison, R. J. (2000). Socioeconomic differences in childhood injury: A population based epidemiologic study in Ontario, Canada. Injury Prevention, 6, 203208.

Forjuoh, S. N., Guyer, B., Strobino, D. M., Keyl, P. M., Diener-West, M., \& Smith, G. S. (1995). Risk factors for childhood burns: A case-control study of Ghanian children. Journal of Epidemiology and Community Health, 49, 189-193.

Fratianne, R. B., \& Brandt, C. P. (1994). Medical management. In K. J. Tarnowski (Ed.), Behavioral aspects of pediatric burns (pp. 23-53). New York, NY: Plenum Press.

Fukunishi, K., Takahashi, H., Kitagishi, H., Matsushima, T., Kanai, T., Ohsawa, H., et al. (2000). Epidemiology of childhood burns in the Critical Care Medical Center of Kinki University Hospital in Osaka, Japan. Burns, 26, 465-469.

Garling, A., \& Garling, T. (1995). Mothers’ anticipation and prevention of unintentional injury to young children in the home. Journal of Pediatric Psychology, 20, 23-36.

Gielen, A. C., Wilson, M. E., Faden, R. R., Wissow, L., \& Harvilchuck, J. D. (1995). In-home injury prevention practices for infants and toddlers: The role of parental beliefs, barriers, and housing quality. Health Education Quarterly, 22, 85-95.

Glik, D., Kronenfeld, J., \& Jackson, K. (1993). Safety behaviors among parents of preschoolers. Health Values, 17, 18-27. 
Greaves, P., Glik, D. C., Kronenfeld, J. J., \& Jackson, K. (1994). Determinants of controllable in-home child safety hazards. Health Education Research, 9, 307-315.

Green, A. R., Fairclough, J., \& Sykes, P. J. (1984). Epidemiology of burns in childhood. Burns, 10, 368-371.

Guyer, B., \& Ellers, B. (1990). Childhood injuries in the United States: Mortality, morbidity, and cost. American Journal of Diseases of Children, 144, 649-652.

Guyer, B., \& Gallagher, S. S. (1985). An approach to the epidemiology of childhood injuries. Pediatric Clinics of North America, 32, 5-15.

Haddon, W. (1980). Advances in the epidemiology of injuries as a basis for public policy. Public Health Reports, 95, 411-421.

Halperin, S. F., Bass, J. L., \& Mehta, K. A. (1983). Knowledge of accident prevention among parents of young children in nine Massachusetts towns. Public Health Reports, 6, 548552.

Harel, Y. (1988). Family psychosocial contributors to childhood injuries. Unpublished doctoral dissertation, University of Michigan.

Harre, N., Field, J., \& Polzer-Debruyne, A. (1998). New Zealand children’s involvement in home activities that carry a burn or scald risk. Injury Prevention, 4, 266-271.

Hazinski, M. F., Francescutti, L. H., Lapidus, G. D., Micik, S., \& Rivara, F. P. (1993). Pediatric injury prevention. Annals of Emergency Medicine, 22, 456-467.

Jan, M. M., Hasanain, F. H., \& Al-Dabbagh, A. A. (2000). Infant and child safety practices of parents. Saudi Medical Journal, 21, 1142-1146. 
Kaslow, N. J., Koon-Scott, K., \& Dingle, A. D. (1994). Family considerations and interventions. In K. J. Tarnowski (Ed.), Behavioral aspects of pediatric burns (pp. 193-215). New York, NY: Plenum Press.

Kazdin, A. E. (1998). Research design in clinical psychology (3rd ed.). Boston: Allyn and Bacon.

Kemp, A., \& Sibert, J. (1997). Childhood accidents: Epidemiology, trends, and prevention. Journal of Accidental Emergency Medicine, 14, 316-320.

Kendrick, D. (1994). Children’s safety in the home: Parents’ possession and perceptions of the importance of safety equipment. Public Health, 108, 21-25.

Klauber, M. R., Barrett-Connor, E., Hofstetter, C. R., \& Micik, S. H. (1986). A population-based study of nonfatal childhood injuries. Preventive Medicine, 15, 139-149.

Klein, D. (1980). Societal influences on childhood accidents. Accident; Analysis and Prevention, $12,275-281$.

Kohen, D. F., Soubhi, H., \& Raina, P. (2000). Maternal reports of child injuries in Canada: Trends and patterns by age and gender. Injury Prevention, 6, 223-228.

Kronenfeld, J. J., \& Glik, D. C. (1995). Unintentional injury: A major health problem for young children and youth. Journal of Family and Economic Issues, 16, 365-393.

Laditan, A. A. O. (1987). Accidental scalds and burns in infancy and childhood. Journal of Tropical Pediatrics, 33, 199-202.

Laffoy, M. (1997). Childhood accidents at home. Irish Medical Journal, 90, 26-27.

Landen, M. G., Bauer, U., \& Kohn, M. (2003). Inadequate supervision as a cause of injury deaths among young children in Alaska and Louisiana. Pediatrics, 111, 328-331. 
Langley, J., Silva, P. A., \& Williams, S. M. (1987). Psychosocial factors in childhood injuries: Results from a longitudinal study. Journal of Safety Research, 18, 73-89.

Lewis, T., DiLillo, D., \& Peterson, L. (2004). Parental beliefs regarding developmental benefits of childhood injuries. American Journal of Health Behavior, 28, S61-S68.

Libber, S. M., \& Stayton, D. J. (1984). Childhood burns reconsidered: The child, the family, and the burn injury. The Journal of Trauma, 24, 245-252.

Liller, K. D., Kent, E., \& McDermott, R. J. (1991). Postpartum patients’ knowledge, risk perceptions, and behaviors pertaining to childhood injuries. Journal of Nurse-Midwifery, 36, 355-360.

Luther, S. L., \& Price, J. H. (1981). Burns and their psychological effects on children. The Journal of School Health, 51, 419-422.

Matheny, A. P. (1987). Psychological characteristics of childhood accidents. Journal of Social Issues, 43, 45-60.

Matheny, A. P. (1988). Injuries among toddlers: Contributions from child, mother, and family. In S. Chess, A. Thomas, \& M. Hertzig (Eds.), Annual progress in child psychiatry and child development 1987 (pp. 521-535). New York: Brunner/Mazel, Inc.

McLoughlin, E., \& McGuire, A. (1990). The causes, cost, and prevention of childhood burn injuries. American Journal of Diseases of Children, 144, 677-683.

Morey, L. C. (1991). Personality Assessment Inventory professional manual. Odessa, FL: Psychological Assessment Resources, Inc.

Morrongiello, B. A., \& Kiriakou, S. (2004). Mothers’ home-safety practices for preventing six types of childhood injuries: What do they do, and why? Journal of Pediatric Psychology, 29, 285-297. 
Morrongiello, B. A., Midgett, C., \& Shields, R. (2001). Don’t run with scissors: Young children's knowledge of home safety rules. Journal of Pediatric Psychology, 26, 105115.

Mott, J. A. (1999). Personal and family predictors of children's medically attended injuries that occurred in the home. Injury Prevention, 5, 189-193.

Paul, C. L., Sanson-Fisher, R. W., Redman, S., \& Carter, S. (1994). Preventing accidental injury to young children in the home using volunteers. Health Promotion International, 9, 241249.

Peterson, L., Mori, L., \& Scissors, C. (1986). Mom or dad says I shouldn’t: Supervised and unsupervised children’s knowledge of their parents' rules for home safety. Journal of Pediatric Psychology, 11, 177-188.

Petridou, E., Trichopoulos, D., Mera, E., Papadatos, Y., Papazoglou, K., Marantos, A., et al. (1998). Risk factors for childhood burn injuries: A case-control study from Greece. Burns, 24, 123-128.

Phillips, W., Mahairas, E., Hunt, D., \& Pegg, S. P. (1986). The epidemiology of childhood scalds in Brisbane. Burns, 12, 343-350.

Rivara, F. P. (1995). Developmental and behavioral issues in childhood injury prevention. Developmental and Behavioral Pediatrics, 16, 362-370.

Rivara, F. P., \& Mueller, B. A. (1987). The epidemiology and causes of childhood injuries. Journal of Social Issues, 43, 13-31.

Rossi, L. A., Braga, E. C. F., Barruffini, R. de CP., \& Carvalho, E. C. (1998). Childhood burn injuries: Circumstances of occurrences and their prevention in Ribeirao Preto, Brazil. Burns, 24, 416-419. 
Saldana, L., \& Peterson, L. (1998). Preventing injury in children: The need for parental involvement. In T. S. Watson \& F. M. Gresham (Eds.), Handbook of child behavior therapy (pp. 221-238). New York: Plenum Press.

Santer, L. J., \& Stocking, C. B. (1991). Safety practices and living conditions of low-income urban families. Pediatrics, 88, 1112-1118.

Schwebel, D. C., Brezausek, C. M., Ramey, S. L., \& Ramey, C. T. (2004). Interactions between child behavior patterns and parenting: Implications for children’s unintentional injury risk. Journal of Pediatric Psychology, 29, 93-104.

Schwebel, D. C., Speltz, M. L., Jones, K., \& Bardina, P. (2002). Unintentional injury in preschool boys with and without early onset of disruptive behavior. Journal of Pediatric Psychology, 27, 727-737.

Sharp, R. J. (1993). Burns. In K. W. Ashcraft \& T. M. Holder (Eds.), Pediatric surgery (pp. 89102). Philadelphia, PA: W. B. Saunders Co.

Simon, P. A., \& Baron, R. C. (1994). Age as a risk factor for burn injury requiring hospitalization during early childhood. Archives of Pediatrics and Adolescent Medicine, 148, 394-397.

Slater, S. J., Slater, H., \& Goldfarb, I. W. (1987). Burned children: A socioeconomic profile for focused prevention programs. Journal of Burn Care and Rehabilitation, 8, 566-567.

Sluckin, W., \& Herbert, M. (Eds.). (1986). Parental behaviour. Oxford: Basil Blackwell.

Smith, R. W., \& O’Neill, T. J. (1984). An analysis into childhood burns. Burns, 11, 117-124.

Sullivan, M., Cole, B., Lie, L., \& Twomey, J. (1990). Reducing child hazards in the home: A joint venture in injury control. Journal of Burn Care and Rehabilitation, 11, 175-179. 
Tarnowski, K. J. (1994). Overview. In K. J. Tarnowski (Ed.), Behavioral aspects of pediatric burns (pp. 1-22). New York, NY: Plenum Press.

Tarnowski, K. J., \& Rasnake, L. K. (1990). Pediatric burns. In A. M. Gross \& R. S. Drabman (Eds.), Handbook of clinical behavioral pediatrics (pp. 231-242). New York, NY: Plenum Press.

Tarnowski, K. J., \& Rasnake, L. K. (1994). Long-term psychological sequelae. In K. J. Tarnowski (Ed.), Behavioral aspects of pediatric burns (pp. 81-118). New York, NY: Plenum Press.

Tremblay, G. C., \& Peterson, L. (1999). Prevention of childhood injury: Clinical and public policy challenges. Clinical Psychology Review, 19, 415-434.

Turegun, M., Celikoz, B., Nisanci, M., \& Selmanpakoglu, N. (1997). An extraordinary cause of scalding injury in childhood. Burns, 23, 170-173.

Varas, R., Carbone, R., \& Hammond, J. S. (1988). A one-hour burn prevention program for grade school children: Its approach and success. Journal of Burn Care and Rehabilitation, 9, 69-71.

Vaughan, E., Anderson, C., Agran, P., \& Winn, D. (2004). Cultural differences in young children's vulnerability to injuries: A risk and protection perspective. Health Psychology, 23, 289-298.

Wortel, E., \& de Geus, G. H. (1993). Prevention of home related injuries of pre-school children: Safety measures taken by mothers. Health Education Research, 8, 217-231.

Wortel, E., de Geus, G. H., Kok, G., \& van Woerkum, C. (1994). Injury control in preschool children: A review of parental safety measures and the behavioral determinants. Health Education Research, Theory, and Practice, 9, 201-213. 
Appendix A

\section{DEMOGRAPHIC QUESTIONNAIRE}

PARTICIPANT \#:

TODAY'S DATE:

\section{I: TARGET CHILD INFORMATION:}

AGE:

DATE OF BIRTH:

SEX (circle): Male Female

RACE (circle): Caucasian African-American

Asian-American Hispanic-American

Other:

MAILING ADDRESS:

HOMETOWN: COUNTY:

WHAT IS YOUR RELATIONSHIP TO THE ABOVE CHILD (for example: mother, father)?

PLEASE LIST THE NAME OF ANY OTHER PERSON(S) WHO ALSO HAS A MAJOR ROLE IN THE DAY-TO-DAY CARE OF THE ABOVE CHILD, AND DESCRIBE HIS OR HER RELATIONSHIP TO THE CHILD (for example: grandparent): 


\section{II: HOUSEHOLD MEMBERS}

In the chart below, please indicate the name, age, gender, work status, and relationship (to the target child) of all ADULTS living in the child's home, including yourself:

\begin{tabular}{|l|c|c|c|c|}
\hline NAME & AGE & $\begin{array}{c}\text { GENDER } \\
\text { (circle one) }\end{array}$ & $\begin{array}{c}\text { WORK STATUS } \\
\text { (circle one) }\end{array}$ & $\begin{array}{c}\text { RELATIONSHIP to } \\
\text { TARGET CHILD }\end{array}$ \\
\hline & & Male & Unemployed & \\
& & Female & Part Time & \\
& & Full Time & \\
\hline & & Male & Unemployed & \\
& & Female & Part Time & \\
\hline & & Full Time & Unemployed & \\
& & Female & Part Time & \\
& & Full Time & \\
\hline & & Male & Unemployed & \\
& & Female & Part Time & \\
& & & Full Time & \\
\hline
\end{tabular}

In the chart below, please indicate the name, age, gender, and relationship (to the target child) of all CHILDREN living in the child's home:

\begin{tabular}{|l|c|c|c|}
\hline NAME & AGE & $\begin{array}{c}\text { GENDER } \\
\text { (circle one) }\end{array}$ & $\begin{array}{c}\text { RELATIONSHIP to } \\
\text { TARGET CHILD }\end{array}$ \\
\hline & & Male & \\
& & Female & \\
\hline & & Male & \\
& & Female & \\
\hline & & Male & \\
& & Female & \\
\hline & & Male & \\
& & Female & \\
\hline & & Male & \\
& & Female & \\
\hline & & Male & \\
& & Female & \\
& & Male & \\
& & Female & \\
\hline
\end{tabular}

1. Does any household member have any special needs (for example, ongoing medical needs due to a chronic illness or disability)? (circle): Yes No

If yes, please describe: 


\section{III: FAMILY CONSTELLATION AND FINANCIAL INFORMATION}

2. Circle the category that best describes your child's family:

Single Parent / Never Married

Single Parent / Separated or Divorced

Single Parent / Widowed
Biological Parents Married

Biological Parent Remarried to Stepparent

Living with Boyfriend or Girlfriend

3. What is your total household income per year? (circle below):

[8] Less than $\$ 15,000$

[7] $\$ 15,000-\$ 24,999$

[6] $\$ 25,000-\$ 34,999$

[5] $\$ 35,000-\$ 44,999$
[4] $\$ 45,000-\$ 54,999$

[3] $\$ 55,000-\$ 64,999$

[2] $\$ 65,000-\$ 74,999$

[1] $\$ 75,000$ or greater

4. Does your child have insurance? (circle): Yes No

If yes, please indicate the name of the insurance policy (s):

5. Does your family receive extra financial assistance (for example, food stamps)? (circle):

Yes No

If yes, please specify:

If yes, please specify the total number of assistance programs that you receive: 


\section{IV: FAMILY SMOKING AND BURN INJURY INFORMATION}

6. For each household member, please indicate the person's current smoking status and history of any medically-treated burn injury:

\begin{tabular}{|l|c|c|}
\hline HOUSEHOLD MEMBER NAME & $\begin{array}{c}\text { SMOKING STATUS } \\
\text { (circle one) }\end{array}$ & $\begin{array}{c}\text { HISTORY OF BURN } \\
\text { INJURY NEEDING A } \\
\text { DOCTOR VISIT } \\
\text { (circle one) }\end{array}$ \\
\hline & Yes \\
No
\end{tabular}

7. Please describe the burn injury history (i.e., number of burn injuries, type of burn injuries, cause of burn injuries, and severity of burn injuries) for any family member who has a burn injury history: 


\section{V: CAREGIVER EDUCATIONAL BACKGROUND}

Please use the following scale to answer item \#8 (below) about caregiver educational background:

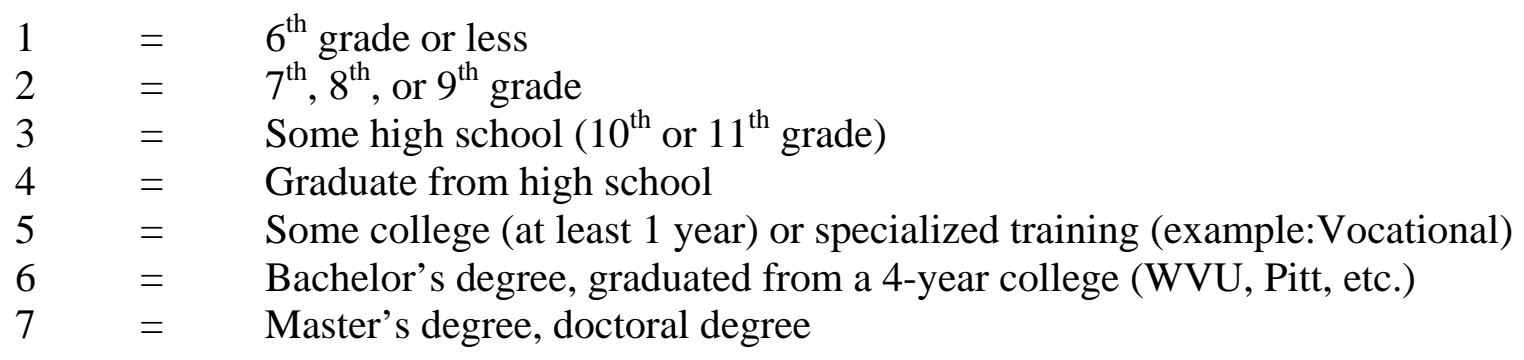

8. Please show the highest level of education completed by the target child's primary caregiver and any other caregiver who provides for the child's daily needs (for example, medical or financial). For each caregiver who is not a biological parent, please write his or her name and who he or she is to the target child (for ex., stepparent) in the parentheses on one of the lines beginning with “Other” below:

$\begin{array}{lll}\text { Biological Mother } & = & - \\ \text { Biological Father } & = & - \\ \text { Other }( & & \\ \text { Other }( & = & \\ \text { Other }(\end{array}$

\section{CAREGIVING INFORMATION}

9. Please list the NAME and RELATION (for example, mother, father, grandparent, babysitter, friend) of any person other than the primary caregiver who sometimes provides care for the target child INSIDE the child's home. For each person listed, please write the AVERAGE NUMBER OF CARE HOURS PER WEEK:

Name:

Relation: Hours/Week:

Name: Relation: Hours/Week:

Name: Relation: Hours/Week:

Name: Relation: Hours/Week:

Name: Relation: Hours/Week: 
10. Please list the NAME and RELATION (for example, daycare provider, friend, relative) of any person other than the primary caregiver who sometimes provides care for the target child OUTSIDE the child's home. For each person listed, please write the PLACE WHERE THE CARE IS GIVEN (e.g., daycare, church, home of a friend or relative) and the AVERAGE NUMBER OF CARE HOURS PER WEEK:

Name: Relation: Place: Hours/Week:

Name: Relation: Place: Hours/Week:

Name: Relation: Place: Hours/Week:

Name: Relation: Place: Hours/Week:

Name: Relation: Place: Hours/Week:

11. How often do older siblings (age 6 years and up) provide care (for example, assist with cooking or bathing) for younger children (age 0-5 years) in your home? (Circle one)
Always
Often
Sometimes
Rarely
Never

12. Please describe who bathes the young children (aged 0-5 years):

13. Think of a typical bath for the target child and please answer the following questions:

(a) How does this child get into the bath?

(b) How does this child get cleaned?

(c) How does this child get out of the bath? 
14. Think of a typical dinner at which the target child is present and please answer the following questions:

(a) Who cooks?

(b) Who is present?

(c) How does the target child get his/her food?

(d) How does the target child eat (for example, who, if anyone, feeds him/her)? 
Appendix B

\section{BURN INFORMATION FORM}

Part 1: Interview with the Family

PARTICIPANT \#:

TODAY'S DATE:

Informant Taking Part:

Age of Pediatric Patient at the Time of the Burn Injury:

Date of the Burn Incident:

Burn Agent (e.g., hot water):

Description of How the Burn Incident Occurred:

Location in the Home Where the Burn Incident Occurred:

Person(s) Present at the Time of the Burn Incident and Their Age(s):

First Aid Procedures Applied in the Home and By Whom: 
Family History of Burn Injuries (CIRCLE one): YES NO

If yes, describe:

Part 2: Medical Chart Review Followed by Confirmation by Burn Care Staff TODAY'S DATE:

Type of Burn (e.g., scald):

Percentage TBSA by Burn Degree and in Total:

\begin{tabular}{|l|l|l|l|}
\hline $\begin{array}{l}\text { TBSA of 1st Degree } \\
\text { Burns }\end{array}$ & $\begin{array}{l}\text { TBSA of 2nd Degree } \\
\text { Burns }\end{array}$ & $\begin{array}{l}\text { TBSA of 3rd Degree } \\
\text { Burns }\end{array}$ & $\begin{array}{l}\text { TBSA in Total (i.e., } \\
\text { of all burns) }\end{array}$ \\
\hline & & & \\
& & & \\
\hline
\end{tabular}

Parts of the Body Burned:

Number of Skin Graft Surgeries and Date of Each:

Other Complications (e.g., pneumonia):

Date of Hospital Admit: Date of Hospital Discharge: 


\section{Appendix C}

\section{The Primary Caregiver Supervisory Index (PCSI)}

Instructions for the Researcher: Ask the parent to imagine being in the following situations. Allow the parent to respond with a brief description of how he/she actually would handle the following situations. If needed, help the parent to focus on what he/she would do in relation to the child who is the focus of the interview. Assure the parent that these are common situations faced by all parents and all answers are acceptable.

1. You are visiting a friend's home. There are matches and a lighted cigarette lying on a table where your child and your friend's children are playing. You would:

2. You are visiting the home of a friend who does not have young children. You and your child are in the kitchen with your friend when the phone rings and it is for you. The phone is in another room in the house. You would:

3. You are making dinner in the kitchen. Something is boiling on the stove and baking in the oven. Your child comes to (or is brought to) the kitchen and demands your attention while the kitchen phone starts ringing. You would: 
4. You are watching your child while he/she is sitting happily outside in an unfenced yard with some toys. You have to go inside for a few minutes. You would:

5. It is time to prepare dinner. You are the only adult in the house. Your child needs to be entertained and kept busy while you cook. You would:

6. You are driving alone in the car with your child who has fallen asleep. You absolutely have to stop at a convenience store to pick up a few quick items. You would:

7. Your child is in the bathtub and has just finished taking his or her bath. You discover that there are no towels in the bathroom. You would: 
8. You are enjoying a swim in a swimming pool during the summer. Your child is by the side of the pool. The babysitter who should be watching your child is nowhere in sight. You would:

9. You are in the bathroom using a curling iron, and your child is watching you get ready. The phone rings in a different room. No one else is in the house. You would:

10. You are at a crowded shopping mall on a Saturday afternoon with your child. You have just made several large purchases, which you are carrying. How would you handle your child in the parking lot on the way back to the car?

11. You are in a restaurant, and the server is holding a tray of hot food above your child while he or she serves. You would: 
12. You are at the playground with your child who is by the jungle gym. An older child who you do not know is playing rough around the younger children on the jungle gym. You would:

13. You are on your way to a friend's house, which is only a few blocks away. Your child starts to fuss about having been fastened in a seat belt. You would:

14. It's time for your child's nighttime bath. Your child is acting up, and you have a headache and are tired. Describe how the bath would go. Specifically, how would the child get in the bath, washed, out of the tub, and dried?

15. You are on a long trip in the car with your child. Your spouse or friend is driving before you stop for the day. Your child is tired and wants to take a nap in your lap. You would: 
16. You are sitting in the kitchen, reading with a cup of coffee in hand. Your child comes to you (or is brought to you) with outstretched arms for your attention. You would:

17. You are home alone with your child who is in bed and asleep for the night. Your good friend, who lives three doors down from you, calls you on the phone and asks you to come over for something important. You will only be gone for 5-10 minutes. You would:

18. As your family comes into the kitchen for dinner, the frying pan on the stove catches on fire. You would: 


\section{Appendix D}

\section{Scoring Guidelines for the Primary Caregiver Supervisory Index (PCSI) (A Supplement to the General Scoring Procedures)}

\section{General Scoring Rules Across Items:}

- If the caregiver indicates that they would do one thing or another, score the least protective/safe behavior.

- If the caregiver states that she would give a verbal directive and use another supervision method (e.g., remove hazard, remove child from hazard, or provide physical supervision), do not score "2." Rather, score the best supervision method used on top of the statement. That is, give a score of “3” or “4,” whichever is most appropriate given the supervision method.

- If no supervision is provided for any hazard in the scenario, give a score of " 1. ."

\section{Specific Scoring Rules by Item Number:}

1. Give a score of " 4 " if the caregiver says that she would ask her friend to remove the matches and lighted cigarette. Give a score of " 1 ” if the caregiver only attends to the lighted cigarette.

2. Give a score of "2" if the caregiver gives verbal instructions to the friend to watch the child. If the caregiver leaves the child with the friend without saying anything, score a " 1. "

3. If the caregiver stops cooking (e.g., turns off the burner) and provides close supervision in the kitchen, give a score of “3,” because the child still is in the kitchen near hazards.

4. If the caregiver is watching the child outside the house or from inside the house, score a " 3. "

5. If the child is engaged in a safe, age-appropriate activity (e.g., watching television, playing with toys in a playpen) out of the kitchen, score "4." If the child is in a movement-limiting device (e.g., high chair) in the kitchen, score "3." If the child is free-roaming in the kitchen, score " 1 " because in this scenario, the caregiver is cooking, not attending to the child.

6. If the caregiver leaves the child in the car, give a score of " 1. " 
7. If the caregiver leaves, even if after taking the child out of the tub, give a score of "1," because no supervision is provided momentarily while the child is around hazards. If the caregiver can see the child when he/she gets the towel, however, score "3."

8. To gain a score of "4," the caregiver must take the child away from the pool or put a bubble/floater on the child and closely monitor the child in the pool. Whether or not the child can swim according to caregiver report, if only close supervision by the caregiver (e.g., watching the child at a close distance) is provided, give a score of "3."

9. If the caregiver stays in the bathroom with the child and ignores the telephone, score "3."

10. Any response in which the caregiver maintains physical contact with the child (e.g., carries child, holds child's hand, holds a stroller with child buckled in) earns a "4."

11. Score " 4 " if the caregiver asks or tells the server to move the hazard away from the child.

12. Any response in which the caregiver strictly gives instructions to the older child who is playing rough around the younger children earns a score of "2."

13. Any response in which the child is not in a seatbelt gets a score of "1." Any response in which the child is in a seatbelt gets a score of " 4 ."

14. If the caregiver skips the bath, score a " 4 ." If the caregiver or another adult physically supervises the child for the entire duration of bath time, give a score of "4."

16. To earn a "4," the caregiver must put the coffee cup out of reach before handling the child. Score a "3" if the cup is put down without concern for placement before the caregiver handles the child. Attending to the child with the cup in hand gets a score of "1."

18. Give a score of "4" if the caregiver puts a lid, baking soda, flour, or a towel on the frying pan. A score of " 4 " also is warranted if the caregiver tells the child to leave the kitchen. Score " 1 " if the caregiver puts water on the pan with the child in the kitchen. 


\section{Appendix E}

\section{The Home Safety Knowledge Interview (HSKI)}

Directions to the Interviewer: For each risk situation, ask the caregiver to think of the target child in the study and describe every safety measure that the caregiver knows to lessen this child's risk of injury, whether or not he/she actually takes the safety measure. In other words, ask the caregiver what he/she could do or not do to protect the target child against an injury in each situation. Make sure that the caregiver knows that any safety instructions to this child count as safety measures. Assure the caregiver that there are no right or wrong answers, and he/she is $\underline{\text { not }}$ expected to know a safety measure(s) for all items.

\section{What could you do or not do....}

1. ....when cooking on top of the stove?*

2. ....with hot items in the kitchen, such as a coffee pot, toaster, cooker, crock pot, or hot drink?*

3. ....with sharp objects like knives and scissors?*

4. ....about the hot water temperature in your home? 


\section{What could you do or not do....}

5. .....with cleaners?*

6. ....if your child is burned?

7. ....when taking hot food or drinks out of the microwave or oven?

8. ....with medicine?*

9. .... when your child is in the bathtub?*

$10 . . .$. if the floor is slippery?* 


\section{What could you do or not do....}

11. ....when lighting a fire (for example, a campfire or fireplace)?

12. ....when burning trash (describe what you know even if not applicable to you)?

13. ....about running in the house?*

14. ....about matches and lighters in your home?*

15. ....if your child's clothes catch on fire?* 


\section{What could you do or not do....}

16. ....about plugging something into an electrical outlet or unplugging something?*

17. ....to keep your child from falling out of a window?*

18. ....about using an iron or curling iron?

19. ....if your child wants something up high on a bookcase or shelf?*

20. ....if the smoke alarm goes off at night while your child is sleeping?* 


\section{What could you do or not do....}

21.....about leaving things on the stairs?*

22. ....if a frying pan lights on fire?

23. ....about your child's behavior when going up or coming down stairs?*

24. ....about your child using the bathroom sink?*

25. ....to detect if there is smoke in your home when you are awake or sleeping? 


\section{What could you do or not do....}

26. ....with things in the kitchen that your child is not supposed to climb on?*

27. ....about the electrical outlets in your home?

28. ....with safety gates in your home?

29. ....when grilling outside on a charcoal grill? 
Appendix F

\section{“Good” Home Safety Responses That Earn a Score of "3” on the Home Safety Knowledge Interview (HSKI)}

Note: Good responses are listed by item number. When there is more than one good response, good responses are separated by a semi-colon.

Reminder: Score the best thing that the caregiver knows to do for each item.

1. Keep the child out of the kitchen using a safety gate.

2. Keep these items out of the child's reach whether on or off; Don't let child in the kitchen when these items are on, and keep these items out of the child's reach when not in use.

3. Keep these objects in a locked place or out of the child's reach.

4. Set the hot water tank at "low"; Set the hot water tank at 120 degrees Fahrenheit or less.

5. Keep in a locked place; Keep in a place that the child cannot reach.

6. Apply cold water and then either call the pediatrician, 911, or an ambulance/hospital.

7. Keep the child out of the kitchen; Keep the child in a strapped baby seat, high chair, or similar device that is away from the microwave/oven, and keep items away from the child.

8. Keep medicine out of reach; Keep medicine in a locked place.

9. Check hot water temperature before putting child in the bath and monitor child in bath; Preset hot water temperature at "low” or 120 degrees Fahrenheit or less and monitor child in bath.

10. Physically keep the child away from the slippery floor; Gate off the floor; Dry the floor.

11. Keep the child away from the fire, supervised by an adult.

12. Keep the child away from where the trash will be burned, supervised by an adult.

13. Do not allow running in the house.

14. Do not keep matches or lighters in the house; Keep matches and lighters out of the child's reach; Keep matches and lighters in a locked place. 
15. Tell and help the child to stop, drop and roll, and apply cold water to the burn; Stop child, smother the fire with a blanket, and apply cold water to the burn.

16. Have safety plugs in all outlets that the child can reach and supervise the child around cords that are plugged into outlets.

17. Use a guard, gate, or stopper on windows that the child can reach and from where a fall injury to the child is possible.

18. Keep these items out of reach when plugged in, whether or not they are in use.

19. Caregiver gets the item for the child; Teach the child to ask an adult to get the item and monitor the child to ensure follow through.

20. Get the child out of the house if possible (e.g., if the pathway to the child is clear and the door to the child's room is not too hot), staying low to the ground to prevent a smoke inhalation injury; Get out of the house and call 911 if cannot get to the child safely.

21. Keep items off the stairs; Gate off the stairs if items are on the stairs.

22. Cover pan with a lid; Keep children out of the kitchen. (Note: applying baking soda or flour gets a “2” because these items usually are not readily accessible. Applying water gets a “ 1 .”)

23. Maintain physical contact with the child while using stairs; If the child is beginning to use stairs independently, maintain physical contact with the child or closely monitor the child on the stairs; If an older child (e.g., 5 years) uses stairs independently without difficulty, have rules about holding onto the banister and taking careful steps, and keep an eye on the child.

24. Set hot water temperature on "low" or at less than 120 degrees Fahrenheit, and allow the child to use the sink independently (if potty trained); Supervise child when using the bathroom sink to make sure he/she does not turn the hot water on.

25. Have a smoke detector with working batteries and check batteries regularly. 
26. Keep the child out of kitchen (e.g., with a safety gate); Monitor the child to make sure that he/she does not climb on these things, saying "no," using physical redirection, and/or implementing negative consequences; Keep the child in a high chair, baby seat, or other belted device in the kitchen; Remove these items from the kitchen, if possible.

27. Put plastic safety plugs in any outlet that the child can reach, even by climbing on things; Put safety plugs in all outlets that are not in use.

28. Use a safety gate for all kitchen and stair openings.

29. Keep the child in the house or otherwise away from the grill, supervised by an adult; Use coals that have been pre-treated with lighter fluid after ensuring that the child is away from grill, supervised by an adult; Apply accelerant according to instructions and pause before lighting the grill, after ensuring that the child is away from grill, supervised by an adult. 
Appendix G

\section{Observed Home Safety Measures (OHSM)}

PARTICIPANT \#:

TODAY'S DATE: OBSERVER'S INITIALS:

Observer Directions: For each item in Part 1, indicate whether the object (i.e., safety device or hazard) as described is "present" or "absent" after going through the home with the primary caregiver. If you do not see an object (e.g., smoke detector), you should ask the caregiver if he/she has it, and, if yes, to show you it. For each item in Part 2, indicate whether the situation or condition is observed to be "safe" or "unsafe" as defined per item.

For all items, circle "NA" for "not able to determine" or "not applicable" if relevant. You might be "not able to determine" a rating because a caregiver refused to let you see a certain item (e.g., water tank) or test an item (e.g., smoke detector). "Not applicable” refers to when a certain item (e.g., electrical outlets) cannot be evaluated because it is not present in the home. If you circle "NA," please explain your reason for doing so in the margin.

\section{PART 1:}

1. Smoke detector:

Present Absent NA

2. Working smoke detector (i.e., test it using the test button):

Present Absent NA

3. Fire extinguisher:

Present Absent NA

4. Fire extinguisher that has not expired:

Present Absent NA

5. Safety lock on any cabinet:

Present Absent NA


6. Safety lock or guard (i.e., any special gadget beyond a regular window lock) on all windows where a fall injury to a young child (0-5 years) in the home is possible:

[Note: A fall injury may be possible from a first floor window depending on the child's age and the distance of the window from the ground.]

$$
\text { Present Absent NA }
$$

7. Electrical outlet plugs on all electrical outlets within reach of young children (0-5 years) in the home:

$$
\text { Present Absent NA }
$$

8. A stove guard (at least one):

$$
\text { Present Absent NA }
$$

9. Stove knob covers on all stove knobs within reach of young children (0-5 years) in the home:

$$
\text { Present Absent NA }
$$

10. Intact fireguards or screens on all working fireplaces:

$$
\text { Present Absent NA }
$$

11. Kitchen safety gate that fits a kitchen door:

$$
\text { Present Absent NA }
$$

12. Stairway safety gate that fits a set of stairs:

$$
\text { Present Absent NA }
$$

13. Any baby walker:

$$
\text { Present Absent NA }
$$

14. Noisy or chaotic (i.e., too loud or chaotic to hear the caregiver without straining):

Present Absent NA


15. Disorder (i.e., articles strewn about with no organization) or clutter (i.e., too many articles for a given space) in any room where any young child (0-5 years) in the home likely spends time (i.e., kitchen, dining room, living room, main hallways, child's bedroom, child's bathroom, and any common bathrooms):

$$
\text { Present Absent NA }
$$

16. Overcrowding (i.e., \# of people + \# indoor, free-roaming pets $\div$ \# of bedrooms in the home is > 2):

Present Absent NA

Number of indoor, free-roaming pets in the home:

Number of bedrooms in the home:

Note: You only need to obtain (through observation) “\# of indoor, free-roaming pets" and "\# of bedrooms" in the home, because "\# of people" in the home is obtained on the Demographic Form. Karen will do the math to determine overcrowding later.

17. Any non-furniture item (e.g., child or animal toy, pet water bowl or food dish, shoes) on the kitchen floor:

Present Absent NA

18. Any item on the stairs:

$$
\text { Present Absent NA }
$$

\section{PART 2:}

19. Accessibility of all cleaners ["Safe" = out of reach of young children ( 0 - 5 years) in the home or within their reach but located in a locked place]:

$$
\text { Safe Unsafe NA }
$$

20. Accessibility of any kitchen item that is hot (e.g., tea cup, coffee pot) or is plugged into an outlet and can become hot (e.g., coffee pot, crock pot, cookers) whether or not the appliance is turned on ["Safe" = out of reach, including cords if applicable, of young children ( $0-5$ years) in the home]:

$$
\text { Safe Unsafe NA }
$$


21. Accessibility of all medicine ["Safe" = out of reach of young children ( $0-5$ years) in the home or within their reach but located in a locked place]:
Safe
Unsafe
NA

22. Hot water temperature ["Safe" = a setting of "low" on the hot water tank or a hot water thermometer reading of 120 degrees Fahrenheit or less after the hot water has run for at least 30 seconds]:
Safe
Unsafe
NA

Hot water tank setting:

Hot water thermometer reading:

Note: Try to get both the hot water tank setting and hot water thermometer reading if possible.

23. Accessibility of kitchen knives and scissors ["Safe" = out of reach of young children (0-5 years) in the home or within their reach but located in a locked place]:
Safe
Unsafe
NA

24. Accessibility of all matches and lighters (if only one applies, rate that one) ["Safe" = out of reach of young children (0-5 years) in the home or within their reach but located in a locked place]:
Safe
Unsafe
NA

25. Accessibility of any clothing iron and curling iron that is plugged into an outlet whether or not the appliance is turned on (rate those that apply) ["Safe" = out of reach, including cords, of young children ( $0-5$ years) in the home or within their reach but located in a locked place]:

$$
\text { Safe Unsafe NA }
$$

26. Accessibility of any space heater that is plugged into an outlet whether or not the device is turned on ["Safe" = out of reach, including cords, of young children ( $0-5$ years) in the home or within their reach but located in a locked place]:
Safe
Unsafe
NA 
Appendix $\mathrm{H}$

\section{Guidelines for Observers Completing the Observational Home Safety Measure (OHSM)}

\section{Instructions By Item \#:}

1. Give credit for (i.e., rate "present”) any smoke detector, regardless of what shape it's in or how dated it may be.

2. Bring a yard stick to be able to push the test button. A working smoke detector should beep when you push the test button. If the smoke detector is making little, successive beeps, the batteries are low. In this case, rate the item "present," but warn the family that the batteries are low. If there is no smoke detector in the home, score "absent" for this item.

4. If there is no fire extinguisher in the home, score "absent” for this item.

5. Do not give credit if the safety lock is broken. Do give credit if the safety lock works, no matter how sophisticated it is.

6. Do not give credit if the safety lock or guard is broken. Do give credit if the safety lock or guard works, no matter how sophisticated it is.

7. If a young child in the home can reach an unplugged outlet by climbing on furniture or any other means then that plug is “within reach” and the item should be rated as "absent.”

9. If a young child in the home can reach an uncovered stove knob by climbing on furniture or any other means then the knob is "within reach" and the item should be rated as "absent." If the caregiver has removed within-reach knobs, leaving the underlying metal sticks exposed, score "absent," because the child still can turn the metal sticks and ignite the burners.

10. Regardless of the type of fireguard (e.g., one that may get hot), score this item as “present” if there is a fireguard. It’s too hard to tell by looking at the fireguard whether or not it may get hot when a fire is lit. 
11. Rate this item as "present” regardless of how good you may perceive the safety gate to be, so long as it fits the kitchen door space or opening.

12. Rate this item as "present" regardless of how good you may perceive the safety gate to be, so long as it fits a set of stairs.

13. Rate this item as "present” if you see a baby walker, regardless of where it's located in or around the home (e.g., the garage or driveway).

15. If there is a "play room,” discount it in making your rating. We want to distinguish homes that are disorderly and cluttered outside of the playroom, since the playroom, by nature, is often disorganized.

16. "Bedroom” is defined as any room intended or designed to be for sleep primarily, as opposed to for cooking, dining, living, and studying, per examples, regardless of whether or not the room actually is used for sleep. Do not count a living room, for example, as a bedroom, just because a family member also sleeps on the couch in the living room.

19. If a young child in the home can reach the object in question by climbing on furniture or any other means, then the item should be considered "within reach.”

20. If a young child in the home can reach the object in question by climbing on furniture or any other means, then the item should be considered "within reach."

21. "Medicine” includes oral medicine, medicinal creams, and vitamins. If a young child in the home can reach medicine by climbing on furniture or any other means, then the item should be considered "within reach," even if the medicine has a safety cap on it. If the medicine has a safety cap, however, make a note indicating so in the margin.

23. If a young child in the home can reach the object in question by climbing on furniture or any other means, then the item should be considered "within reach.” 
24. If a young child in the home can reach the object in question by climbing on furniture or any other means, then the item should be considered "within reach.” This rule applies even if the lighters are child proof; however, make a note if they are as such.

25. If a young child in the home can reach the object in question by climbing on furniture or any other means, then the item should be considered "within reach.”

26. If a young child in the home can reach the object in question by climbing on furniture or any other means, then the item should be considered "within reach.” 
Table 1

Balanced Demographic Variables by Group

\begin{tabular}{|c|c|c|c|c|}
\hline Child Variables & Case & & Comparison & \\
\hline & $n$ & $\%$ & $n$ & $\%$ \\
\hline Age in months $(M \pm S D)^{\mathrm{a}}$ & $26.40 \pm 14.76$ & & $24.60 \pm 16.70$ & \\
\hline Male/Female & $18 / 12$ & $60 / 40$ & $15 / 15$ & $50 / 50$ \\
\hline Caucasian/Racial minority & $25 / 05$ & $83 / 17$ & $26 / 04$ & $87 / 13$ \\
\hline Urban or suburban/Rural & $8 / 22$ & $27 / 73$ & $6 / 24$ & $20 / 80$ \\
\hline Extra financial aid/No extra & $11 / 19$ & $37 / 63$ & $6 / 24$ & $20 / 80$ \\
\hline financial aid & & & & \\
\hline PC marital status & & & & \\
\hline Single & 9 & 30 & 6 & 20 \\
\hline Married & 17 & 57 & 18 & 60 \\
\hline Living with partner & 4 & 13 & 6 & 20 \\
\hline
\end{tabular}

Note. $\mathrm{PC}=$ primary caregiver.

${ }^{\mathrm{a}}$ Mean and standard deviation scores for each group include 30 children. 
Table 2

Family Demographic and Household Information

\begin{tabular}{|c|c|c|c|c|}
\hline \multirow[t]{2}{*}{ Variables } & \multicolumn{2}{|l|}{$\underline{\text { Case }}$} & \multicolumn{2}{|c|}{$\underline{\text { Comparison }}$} \\
\hline & $M$ & $S D$ & $M$ & $S D$ \\
\hline Number of adults in home & 01.93 & 00.64 & 01.93 & 00.58 \\
\hline Number of children in home & 02.27 & 01.36 & 01.77 & 01.01 \\
\hline Primary caregiver (PC) age in years & 30.17 & 06.47 & 29.57 & 05.89 \\
\hline Number of public financial assistance programs & 00.83 & 01.29 & 00.43 & 00.90 \\
\hline Number of smokers in home & 00.97 & 00.93 & 00.67 & 00.96 \\
\hline Alternate care hours/week in home & 33.60 & 45.20 & 27.99 & 49.54 \\
\hline \multirow[t]{2}{*}{ Alternate care hours/week out of home ${ }^{a}$} & 16.00 & 23.89 & 15.70 & 24.73 \\
\hline & $n$ & $\%$ & $n$ & $\%$ \\
\hline PC unemployed & 9 & 30 & 14 & 47 \\
\hline PC employed part-time or full-time & 21 & 70 & 16 & 53 \\
\hline PC received $\leq$ high school education & 12 & 40 & 8 & 27 \\
\hline PC received $>$ high school education & 18 & 60 & 22 & 73 \\
\hline Household income $<\$ 45,000$ per year & 22 & 73 & 16 & 55 \\
\hline Household income $\geq \$ 45,000$ per year & 8 & 27 & 13 & 45 \\
\hline Medicaid or no insurance for child & 6 & 20 & 8 & 27 \\
\hline Non-medicaid insurance for child & 24 & 80 & 22 & 73 \\
\hline Older siblings never provide care for young kids & 21 & 70 & 25 & 83 \\
\hline Older siblings provide care for young kids & 9 & 30 & 5 & 17 \\
\hline
\end{tabular}

Note. All group means and standard deviations include 30 participants, unless otherwise note. ${ }^{\mathrm{a}} n=29$ in the case group. 
Table 3

Caregiver Psychopathology, Parenting Stress, and Home Safety Knowledge and Behaviors

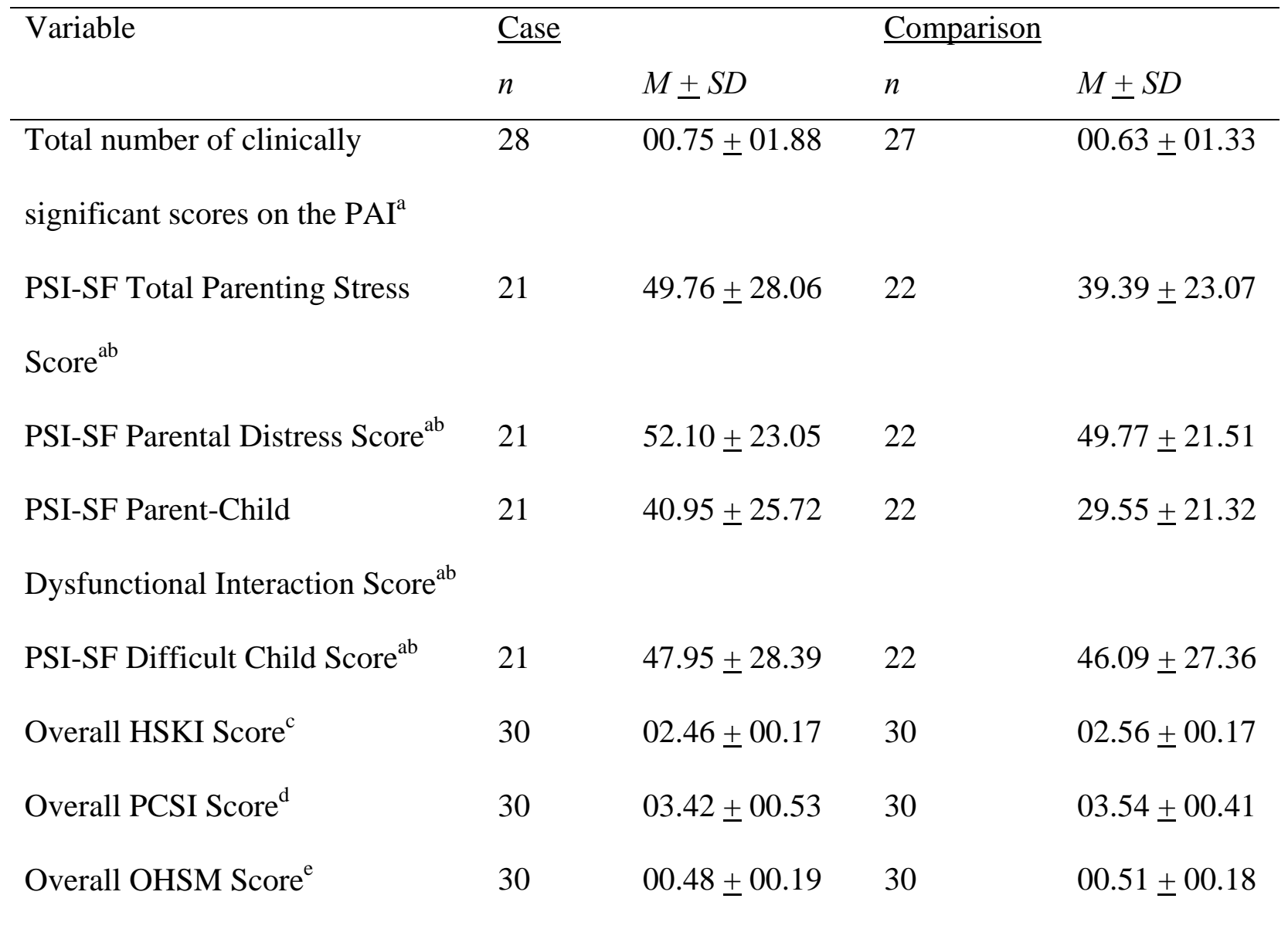

Note. PAI = Personality Assessment Inventory, PSI-SF = Parenting Stress Index - Short Form, HSKI = Home Safety Knowledge Interview, PCSI = Primary Caregiver Supervisory Index, and OHSM = Observed Home Safety Measures.

${ }^{\mathrm{a}}$ Missing participants are due to invalid responding. ${ }^{\mathrm{b}}$ Percentile scores are presented for interpretation; however, raw scores were used in relevant data analyses. 'Overall HSKI Scores ranged from “1” (i.e., “poor” safety knowledge) to “3” (i.e., "good” safety knowledge). 'Overall PCSI Scores ranged from “1” (i.e., no supervision) to “4” (i.e., highest level of supervision; child removed from hazard or hazard removed from child). 'Overall OHSM Scores ranged from “0” (i.e., “poor” safety practice) to “1” (i.e., “good” safety practice). 
Table 4

Clinically Significant Scales Endorsed by Participants on the Personality Assessment Inventory (PAI)

\begin{tabular}{|c|c|c|c|c|}
\hline \multirow[t]{2}{*}{ PAI Scale } & \multicolumn{2}{|l|}{ Case } & \multicolumn{2}{|c|}{ Comparison } \\
\hline & $n$ & $\%$ & $n$ & $\%$ \\
\hline Anxiety & 2 & 7 & 3 & 11 \\
\hline Anxiety-related disorders & 3 & 11 & 2 & 7 \\
\hline Depression & 2 & 7 & 3 & 11 \\
\hline Paranoia & 2 & 7 & 3 & 11 \\
\hline Borderline features & 2 & 7 & 1 & 4 \\
\hline Schizophrenia & 1 & 4 & 1 & 4 \\
\hline Somatic complaints & 1 & 4 & 0 & 0 \\
\hline Mania & 1 & 4 & 0 & 0 \\
\hline Antisocial features & 1 & 4 & 0 & 0 \\
\hline Stress & 3 & 11 & 1 & 4 \\
\hline Suicidal ideation & 1 & 4 & 1 & 4 \\
\hline Treatment rejection & 2 & 7 & 0 & 0 \\
\hline Nonsupport & 0 & 0 & 1 & 4 \\
\hline Warmth & 0 & 0 & 1 & 4 \\
\hline
\end{tabular}

Note. Percents are calculated out of the total number of valid responders (i.e., 28 for the case group and 27 for the comparison group). 
Table 5

Correlations between Predictor Variables and Outcome Variables

\begin{tabular}{|c|c|c|c|}
\hline \multirow[t]{2}{*}{ Predictor Variables } & \multicolumn{3}{|l|}{$\underline{\text { Outcome Variables }}$} \\
\hline & Pediatric Burn Injury ${ }^{\mathrm{a}}$ & PC Supervision & $\begin{array}{l}\text { PC Home } \\
\text { Hazard Control }\end{array}$ \\
\hline PC psychopathology & $-.04(n=55)$ & $-.16(n=55)$ & $-.21(n=55)$ \\
\hline PC parenting stress & $-.17(n=43)$ & $.03(n=43)$ & $-.38 *(n=43)$ \\
\hline PC home safety knowledge & $.27^{*}$ & $.29 *$ & .14 \\
\hline PC supervision & .12 & ---- & .05 \\
\hline PC home hazard control & .08 & .05 & ---- \\
\hline Number of adults in home & .00 & .16 & -.03 \\
\hline Number of children in home & -.21 & -.16 & -.19 \\
\hline$P C$ age in years & -.05 & -.16 & $.25^{*}$ \\
\hline PC education & .20 & .10 & $.35 * *$ \\
\hline PC work hours & -.16 & -.05 & -.07 \\
\hline Other caregiver work hours & $.09(n=49)$ & $-.18(n=49)$ & $.36 *(n=49)$ \\
\hline Family financial status $^{\mathrm{b}}$ & $-.08(n=59)$ & $-.12(n=59)$ & $-.37 * *(n=59)$ \\
\hline Frequency of sibling care & -.19 & .05 & -.09 \\
\hline Number of smokers in home & -.16 & -.02 & $-.39 * *$ \\
\hline Other care hours/week in home & -.06 & -.04 & -.03 \\
\hline $\begin{array}{l}\text { Other care hours/week out of } \\
\text { home }\end{array}$ & $-.01(n=59)$ & $.00(n=59)$ & $-.12(n=59)$ \\
\hline Target child age in months & ---- & $-.53 * *$ & $-.28 *$ \\
\hline
\end{tabular}

Note. $\mathrm{PC}=$ primary caregiver. $N=60$ for all correlations unless otherwise noted in parentheses.

${ }^{\mathrm{a}}$ Higher values reflect the absence of a pediatric burn injury. ${ }^{\mathrm{b}}$ Higher values reflect lower financial status.

$* p<.05, * * p<.01$. 
Table 6

Pictorial Representation of Proposed Discriminant Function and Hierarchical Regression Analyses

\begin{tabular}{lll}
\hline Analysis Type & Discriminant Function Analysis & Hierarchical Regression Analysis \\
\hline Dependent variables & Burn injury occurrence & Home safety behaviors \\
& (dichotomous) & (continuous) \\
\hline Independent variable & Family demographic factors & Family demographic factors \\
cluster 1 (entered first) & & \\
Independent variable & Parenting stress and & \\
cluster 2 & psychopathology & Parenting stress and \\
& & psychopathology \\
Independent variable & Home safety knowledge and & Home safety knowledge \\
cluster 3 (entered last) & behaviors & \\
& &
\end{tabular}


Table 7

Summary of Hierarchical Regression Analysis for Variables Predicting Caregiver Supervision

\begin{tabular}{lllll}
\hline Predictor Variable & $B$ & $\beta$ & $R^{2}$ & $R^{2}$ Change $F$ \\
& (in final model) & (in final model) & & \\
& &
\end{tabular}

Step 1

$\begin{array}{llllll}\text { Child age (months) } & -.02 & -.50 * * & .28 & .28 * * & 22.97 * *\end{array}$

Step 2

$\begin{array}{llllll}\text { Overall HSKI Score }^{\mathrm{a}} & .60 & .23 * & .33 & .05 * & 14.28 * *\end{array}$

Note. $N=60$.

${ }^{\mathrm{a}}$ HSKI = Home Safety Knowledge Interview.

$* p<.05, * * p<.001$. 
Table 8

Summary of Hierarchical Regression Analysis for Variables Predicting Caregiver Home Hazard Control

Predictor Variable $\quad B \quad \beta \quad \beta \quad R^{2} \quad R^{2}$ Change $F$

(in final model) (in final model)

Step 1

Family financial status

Number household smokers

Other caregiver’s work status $\quad-.001$

Step 2

PSI-SF Total Parenting Stress - -.005

Score $^{\mathrm{a}}$

Note. $N=33$.

${ }^{\mathrm{a}}$ PSI-SF $=$ Parenting Stress Index - Short Form.

$* p<.05$.

$\begin{array}{lll}.22 & .22 & 2.73\end{array}$

$-.11$

$-.35$

$-.01$

$.31 \quad .09 \quad 3.17^{*}$

$-.36$ 